\title{
DERECHO Y POLÍTICAS AMBIENTALES EN LAS ISLAS BALEARES (SEGUNDO SEMESTRE 2016)
}

\author{
p. $1-26$
}

\section{DRET I POLÍTIQUES AMBIENTALS A LES ILLES BALEARS (SEGON SEMESTRE 2016)}

\author{
p. 27-50 \\ JosÉ MANUEL GÓMEZ GONZÁLEZ \\ Assessor jurídic del Servei d'Ordenació del Territori \\ Departament de Territori i Infraestructures \\ Consell Insular de Mallorca
}

\begin{abstract}
Sumario: 1. Introducción. 2. Actividad legislativa. 2.1. Aprobación de la Ley 12/2016, de 17 de agosto, de Evaluación Ambiental de las Illes Balears. 2.2. Tramitación del Proyecto de Ley de declaración del Parque Natural de Es Trenc-Salobrar de Campos. 2.3. Aprobación de un decreto de sequía en Ibiza. 3. Políticas de protección del medio marino. 3.1. Aprobada la creación de la Reserva Marina del Freu de Sa Dragonera. 3.2. En estudio la ampliación del Parque Nacional Marítimo-Terrestre del Archipiélago de Cabrera. 3.3. El problema jurídico de las prospecciones en el Mediterráneo. A. Comunicación a Bruselas de la inquietud por las prospecciones. B. Archivo del procedimiento impulsado por Schlumberger. 4. Políticas de protección de la diversidad biológica. 4.1. Propuesta de creación del corredor de cetáceos del Mediterráneo. 4.2. Programa de control de serpientes. 4.3. Programa de control de la avispa asiática. 4.4. Programa de potenciación de la posidonia y de control de especies invasoras. 5. Conservación in situ en espacios naturales. 5.1. La zona de Son Bosc se reincorporará al Parque Natural de S'Albufera. 5.2. Introducción del milano real en el Parque Natural de Mondragó. 5.3. Cría del ibis negro en el Parque Natural de S'Albufera de Mallorca. 6. Políticas sobre los recursos hídricos. 7. Política de residuos. 8. Sobre la aplicación del impuesto del turismo sostenible.
\end{abstract}

\section{Introducción}

Si puede destacarse un aspecto en esta nueva etapa que arrancó con la IX legislatura, es la amplitud de las políticas ambientales y el incremento de su protagonismo en la agenda política. Como contrapunto podríamos plantear la lentitud en la adopción de determinadas medidas que hace años que constituyen una reivindicación constante del movimiento ecologista y de protección ambiental del archipiélago. 
Es evidente que el panorama está mejorando y que se han adoptado normativas de gran importancia encaminadas a revertir el proceso de "barra libre" (disculpen la expresión) que se configuró en la legislatura anterior, en la que el medio ambiente fue marginado a favor del crecimiento económico a cualquier precio, especialmente a costa de penalizar la conservación y de implantar una permisividad que, además de atentar contra toda lógica ambiental, no sirvió para diversificar la vulnerable economía isleña, que descansa casi exclusivamente en el monocultivo turístico.

En la crónica de este semestre no abundan las novedades legislativas dado que las primeras medidas fueron de freno a los desmanes de la legislatura anterior y la actividad parlamentaria de este semestre ha priorizado las políticas sociales por encima de las ambientales. Sin embargo, podemos destacar la aprobación de la ley autonómica de evaluación ambiental, pendiente desde el 2013, que ha optado por reconocer la utilidad procedimental de la legislación básica estatal y se ha limitado a perfilar las especificidades derivadas de la especial condición ambiental de nuestro archipiélago.

No se han producido otras novedades normativas relevantes. Solamente podemos destacar instrumentos normativos en tramitación o normas de carácter menor. En cualquier caso, lo más destacable es el avance en la tramitación de la ley que ha de aprobar la creación del Parque Natural de Es Trenc-Salobrar de Campos, una deuda histórica pendiente con el conservacionismo balear (y más concretamente con el mallorquín), y la adopción de medidas extraordinarias en Ibiza a causa de la sequía que afecta a esa isla.

En cuanto a la aplicación de políticas de gestión, la crónica es más abundante. El recorrido que haremos comprende políticas de protección del medio marino, con la creación de nuevas reservas y la importante ampliación del Parque Nacional Marítimo-Terrestre del Archipiélago de Cabrera, o las propuestas de cese de actividades perniciosas en el Mediterráneo o la creación de un corredor para cetáceos.

Las políticas de conservación de la diversidad biológica, en aplicación de los compromisos internacionales adoptados, también avanzan, aunque la lucha se está centrando en los efectos de la globalización que provocan la introducción de especies invasoras de origen exótico.

Finalmente, analizaremos algunas iniciativas que justifican la importancia de la gestión de los parques naturales como herramientas de conservación in situ muy efectivas para la recuperación de especies y como aportación a la mejora de la diversidad biológica. 
También proponemos alguna noticia en materia de residuos, agua o conservación en relación con la recaudación del impuesto del turismo sostenible o "Ecotasa".

\section{Actividad legislativa}

2.1. Aprobación de la Ley 12/2016, de 17 de agosto, de Evaluación Ambiental de las Illes Balears

Con algún retraso respecto a las previsiones emanadas de la Ley 21/2013, de 9 de diciembre, de Evaluación Ambiental (LEA) (aprobada por las Cortes Generales y publicada en el Boletín Oficial del Estado, número 296, de 11 de diciembre de 2013), la Comunidad Autónoma de las Illes Balears ha aprobado una ley propia de evaluación ambiental que recoge en su mayor parte el texto básico estatal. Dicha ley autonómica añade un procedimiento específico y diversos supuestos adaptados a la realidad insular. Esta nueva ley también incorpora los principios de transparencia de la actuación administrativa y modernización de la Administración con el impulso de la tramitación electrónica.

Así, la Ley 12/2016, de 17 de agosto, deroga y sustituye la Ley 11/2006, de 14 de septiembre, de evaluaciones de impacto ambiental y evaluaciones ambientales estratégicas en las Illes Balears, a fin de ofrecer una mayor seguridad jurídica y simplificar los procedimientos adaptándolos a las previsiones estatales. La nueva LEA balear se configura como un instrumento fundamental para compatibilizar la protección del medio ambiente, el bienestar ciudadano y la salud con el desarrollo económico y social del archipiélago, teniendo en cuenta las peculiaridades de un sistema insular sensible y limitado, aunque de una lectura detenida del nuevo texto autonómico se desprende que se adopta casi íntegramente el procedimiento implantado en la legislación básica estatal. Este cambio legislativo viene motivado por la obligación de adaptarse a la mencionada legislación estatal, que se modificó en el 2013, con una incidencia mayor en la concepción de los procesos participativos, la transparencia y la simplificación de determinados trámites. El nuevo marco de evaluación ambiental considera que la información pública no es únicamente un trámite sino un aspecto esencial, motivo por el que se incorporan los medios electrónicos como forma habitual de comunicación, a lo que hay que añadir que los proyectos se tienen que publicar íntegramente en la web corporativa para general conocimiento. 
Igualmente, en la medida de lo que permiten la regulación básica y la complejidad de la materia, la Ley 12/2016 procura simplificar la tramitación sin perder el rigor ni la exigencia en la preservación ambiental, por ejemplo, exonerando una serie de obras menores de la autorización administrativa preceptiva que ha de emitir la Administración hidráulica. También se simplifica la tramitación de los proyectos que afectan a la red Natura 2000 en los casos en que no repercutan de manera apreciable sobre los espacios. Y es que la Ley 21/2013 prevé que los planes, los programas y los proyectos que, sin tener relación directa con la gestión de un lugar red Natura 2000 o sin ser necesarios para esta gestión, puedan afectar de manera apreciable a estos lugares o espacios, ya sea individualmente o en combinación con otros planes, programas o proyectos, se deben evaluar con los procedimientos que prevé la legislación estatal. Por este motivo, la Ley 12/2016 dedica su título IV a la evaluación de las repercusiones en los espacios red Natura 2000, con las especificidades mencionadas.

Por otro lado, también se ha tenido que adaptar la Ley 5/2005, de 26 de mayo, para la conservación de los espacios de relevancia ambiental (LECO), a la nueva normativa europea y estatal básica, por lo cual la disposición final segunda de la Ley 12/2016 modifica el artículo 39 de la LECO para regular el procedimiento de repercusiones. Igualmente, la disposición final segunda modifica la LECO y actualiza las regulaciones de uso público de los espacios de relevancia ambiental procurando hacerlos compatibles con el acceso al medio natural, en concreto los caminos existentes para acceder a la costa. La Ley recoge también un acuerdo unánime del Parlament de las Islas Baleares sobre la necesidad de regular y controlar la actividad conocida como party-boats, una moda en alza que comienza a provocar algunos impactos ambientales importantes, especialmente en zonas biológicamente sensibles. Asimismo, se ha facultado al Consell de Govern de les Illes Balears para proteger espacios sin tener que contar con el visto bueno del $50 \%$ de los propietarios del área a proteger.

También cabe destacar la previsión que realiza la Ley 12/2016 de obligar al Estado a consultar al órgano ambiental balear, la Comisión de Medio Ambiente de las Islas Baleares (CMAIB), cuando los proyectos que evalúe afecten a la Comunidad Autónoma. Así, se prevé expresamente que la CMAIB tendrá que emitir un informe preceptivo.

En cuanto a la democratización y transparencia de los procedimientos de evaluación ambiental, uno de los elementos más seguros para medir la calidad de una democracia es la transparencia informativa; así lo entiende la Unión Europea, que en la Carta de los 
Derechos Fundamentales (Tratado de Lisboa) incluye el derecho de acceso a los documentos (artículo 42), desplegado en la Directiva 2003/98/CE del Parlamento Europeo y del Consejo, de 17 de noviembre de 2003, relativa a la reutilización de la información del sector público, modificada por la Directiva 2013/37/UE del Parlamento Europeo y del Consejo, de 26 de junio de 2013. El Convenio 205 del Consejo de Europa, sobre acceso a documentos públicos, de 2009, a pesar de que no ha sido ratificado por España, se ha convertido en un hito en materia de regulación de la transparencia y ha influido en la Ley 19/2013, de 9 de diciembre, de transparencia, acceso a la información pública y buen gobierno. En esta misma línea, la nueva LEA autonómica profundiza en la utilización de medios electrónicos como sistema habitual de comunicación para facilitar la participación, la transparencia y el acceso a la información, en la línea de la legislación básica sobre el procedimiento administrativo y de la Ley 11/2007, de 22 de junio, de acceso electrónico de los ciudadanos a los Servicios Públicos. Sin embargo, sobre esta materia todavía queda mucho recorrido por realizar dado el retraso en la implantación de la Administración electrónica que se arrastra.

En la medida en que lo permiten la regulación básica y la complejidad de la materia, también procura simplificar la tramitación sin perder el rigor y la exigencia en la preservación ambiental, tanto en el procedimiento de evaluación ambiental mismo como en el de repercusiones de la Ley 5/2005. En esta misma línea, la disposición final tercera exonera de la autorización administrativa preceptiva de la Administración hidráulica una serie de obras y actuaciones menores.

En general, esta nueva legislación autonómica se plantea como un apéndice de la Ley 21/2013, que pasa a ser una norma de aplicación directa. Así, se ha descartado la opción de transcribirla íntegramente, como parecía ser la intención de algunas comunidades autónomas, y se ha preferido circunscribir la regulación autonómica al despliegue normativo de las especificidades en las Islas Baleares, salvo cuando se ha considerado que era más práctico y claro refundir la regulación de la ley básica con las especificidades de la normativa de las Islas Baleares.

La Ley consta de seis títulos, incluido el preliminar, una disposición adicional, una disposición transitoria, una disposición derogatoria, ocho disposiciones finales y cuatro anexos.

El título preliminar, además de establecer el objeto y el alcance de la Ley, también recoge, entre las finalidades de la norma, los principios de derecho internacional, europeo y de la 
legislación básica porque se ha considerado oportuno reproducirlos al inicio de la Ley, junto con los principios de cooperación interadministrativa. Asimismo, tal como se ha apuntado, se regulan el compromiso con la participación, la transparencia y la Administración electrónica y el conflicto entre la publicidad y la confidencialidad de los datos.

El título I confirma la Comisión de Medio Ambiente de las Islas Baleares como el órgano ambiental del archipiélago, establece su estructura e introduce la novedad del carácter público de las sesiones del Pleno.

El título II regula estrictamente los procedimientos de evaluación ambiental. En despliegue de la normativa básica, y para evitar procedimientos innecesarios, la Ley se acoge al artículo 3.5 de la Directiva 2001/42/CE para establecer qué planes o modificaciones no tienen efectos significativos en el medio ambiente, o entiende que estos serán favorables y que, por lo tanto, no están sujetos a los procedimientos de evaluación ambiental estratégica, excepciones ya recogidas en la derogada Ley 11/2006.

En la documentación de los estudios de impacto ambiental se ha incluido, además del contenido mínimo que establece la ley básica, un anexo de incidencia paisajística que tiene presente tanto el activo que representa el paisaje en las Islas Baleares como la vigencia del Convenio Europeo del Paisaje, aprobado por el Consejo de Europa el 20 de octubre de 2000, que entró en vigor en el Estado español el 1 de marzo de 2008.

El título III regula de manera específica la consulta preceptiva al órgano ambiental de la Comunidad Autónoma en el caso de los planes, los programas y los proyectos que tiene que evaluar la Administración general del Estado.

El título IV trata sobre la evaluación de las repercusiones en los espacios red Natura 2000, en la línea expuesta.

Finalmente, el título V regula unas materias especialmente importantes en la evaluación ambiental pero que a menudo se negligen en la práctica: el seguimiento de los procedimientos ambientales, la protección de la legalidad ambiental, el restablecimiento del orden jurídico perturbado y el régimen sancionador. 


\subsection{Tramitación del Proyecto de Ley de declaración del Parque Natural de Es Trenc-}

\section{Salobrar de Campos}

Ya habíamos tratado en una crónica anterior el proceso de elaboración de un proyecto de ley para declarar parque natural este espacio natural histórico y emblemático de Mallorca. Así, dimos cuenta de las características y vicisitudes del Anteproyecto de Ley de declaración del Parque Natural de Es Trenc-Salobrar de Campos, proyecto normativo y de declaración singular que se somete ahora a un segundo período de exposición pública del que no tenemos resultado al cierre de esta crónica. De hecho, el Govern inició este trámite de forma voluntaria, confiriendo un mes a los posibles interesados como consecuencia de la modificación sustancial del texto inicial a raíz de las 97 alegaciones recibidas en el primer período de exposición pública. Este nuevo Anteproyecto de Ley de declaración del Parque Natural de Es Trenc-Salobrar de Campos ha sido publicado en el Boletín Oficial de las Islas Baleares (BOIB) después de que el texto se viera sometido a una modificación sustancial que hacía recomendable exponerlo nuevamente a la luz pública.

Esta segunda exposición pública ha durado un mes con el objetivo de dar un valor añadido al proceso participativo en la elaboración de la Ley. En este sentido, no solo se publicó y se dio difusión a la iniciativa a través del BOIB, sino que el Anteproyecto se publicó también en la página web de la Consejería de Medio Ambiente, Agricultura y Pesca (http://maap.caib.es) y en la de la Dirección General de Participación y Transparencia (http://participaciociutadana.caib.es).

Analizados los dos textos, el inicial y el segundo anteproyecto expuesto al público, pasamos a explicar las principales novedades del nuevo borrador.

Se modifican los límites para dejar fuera de la zona de influencia el Club Nàutic Sa Ràpita a petición de los concesionarios del puerto y de Puertos de las Islas Baleares; se añaden como actividades prohibidas los tendidos eléctricos y el vuelo a motor a baja altura a petición del Grup Balear d'Ornitologia i Defensa de la Naturalesa (GOB); se especifica más detalladamente el contenido del Plan de Ordenación de los Recursos Naturales (PORN), lo que ofrece una mayor cobertura al régimen del Parque Natural; y se implanta un nuevo artículo sobre la restauración ambiental de las zonas degradadas que existen en la zona. 
Por otro lado, en relación con la creación de la Junta Asesora del Parque, dado el gran interés despertado y el hecho de que numerosas organizaciones expresaron la voluntad de tener representación, se ha respetado la composición inicialmente propuesta ya que se trata de un órgano consultivo y transitorio hasta la aprobación de una reglamentación propia.

El nuevo borrador modifica la disposición adicional y se cambia la denominación que se refería a "accesos" por la de "itinerarios". Respecto de la cifra de 1.500 vehículos, se matiza que se adopta de forma transitoria hasta la aprobación del PORN, herramienta de ordenación que fijará un número definitivo y la ubicación de las infraestructuras necesarias. En esta misma línea se aceptó la alegación del Ayuntamiento de Campos para incluir expresamente una disposición en la Ley que establece que los beneficios generados en la gestión de los equipamientos de aparcamiento revertirán en la conservación del espacio.

Asimismo, el nuevo texto elimina las disposiciones finales primera y segunda de modificación de las DOT (Directrices de Ordenación del Territorio) y de la LECO (Ley $5 / 2005$, de 26 de mayo, para la conservación de los espacios de relevancia ambiental) dado que se trata de una ley singular y las modificaciones que se proponían en tales disposiciones eran más propias de una ley general. Esta supresión se realizó a sugerencia de la Abogacía de la Comunidad Autónoma y del GOB.

Siguiendo con los problemas que genera el régimen actual de acceso al espacio natural, especialmente a las playas que alberga y más concretamente en el período veraniego, se acepta la alegación del Consorcio de Transportes de Mallorca para garantizar la llegada de los autobuses a las zonas de acceso al futuro Parque Natural, medida que persigue favorecer el uso del transporte público y alejar el transporte privado de las proximidades de las playas.

Igualmente, se recogen gran parte de las alegaciones de la Abogacía de la Comunidad Autónoma; por ejemplo, que la declaración de aparcamientos fuera de ordenación tiene que afectar a los parkings privados de uso público, dado que actualmente existen espacios de aparcamiento informal, con y sin licencia o con autorizaciones caducadas o irregulares, que plantean problemas serios de responsabilidad y de incompatibilidad con la conservación de los valores del espacio natural (que además es Natura 2000). 
Finalmente, la documentación expuesta al público se complementa con un estudio multicriterio que analiza las alternativas de los aparcamientos escogidos. En cuanto al estacionamiento de vehículos, se reubica el aparcamiento de Ses Covetes para dar respuesta a gran número de alegaciones que proponen que dicha zona de acceso y aparcamiento se sitúe finalmente en un espacio que ahora mismo ya está degradado y resulta de difícil recuperación. Igualmente, siguiendo con la problemática derivada de los accesos y el aparcamiento (un problema histórico y fundamental en este espacio natural), se suprime el aparcamiento de la zona de Sa Barralina para situarlo en el núcleo urbano de Sa Ràpita, cerca de la zona urbana, y en todos los casos se reducen las dimensiones de las zonas inicialmente previstas como zonas de estacionamiento con el fin de adaptarlas a la capacidad real que deberían tener, especialmente con relación a la capacidad de carga del espacio natural.

\subsection{Aprobación de un decreto de sequía en Ibiza}

Las Islas Baleares están sufriendo los efectos de unos años de escasa pluviometría. En Mallorca las reservas de los embalses se encuentran en mínimos históricos, en Menorca la salinización y la nitrificación de pozos plantean serios problemas, y en Ibiza se han tenido que adoptar medidas extraordinarias mediante un decreto del Consell de Govern de les Illes Balears.

Este decreto declara la situación de sequía extraordinaria en la isla de Ibiza y adopta medidas urgentes y excepcionales de gestión de los recursos hídricos para paliar y corregir sus efectos. Como consecuencia de unos años de baja pluviometría y de una problemática estructural de falta de equilibrio en el balance hídrico por sobreexplotación de los acuíferos, la isla de Ibiza presenta una situación crítica con respecto a las reservas de agua.

La estacionalidad de la pluviometría es incierta, pero mientras no se normalice el régimen de precipitaciones y no se busquen fuentes de suministro de agua alternativas no naturales, no se puede garantizar que se pueda atender la demanda de agua en la isla. Por ello, se adopta el Decreto, que tiene como finalidad controlar al máximo posible la disposición y el uso de agua, y, como objetivo final, recuperar las masas. Esto obliga, por una parte, a adoptar medidas temporales que permitan un incremento del recurso disponible hasta que los niveles de reserva mejoren, y, por otra, a adoptar las medidas administrativas 
necesarias que permitan corregir esta situación mediante la limitación y la restricción de los aprovechamientos de manera equitativa y solidaria entre los sectores afectados.

Para incrementar la disponibilidad de agua, el Decreto prevé que mientras dure la situación de sequía no se puedan efectuar nuevas captaciones en determinadas cuencas que se hallan sobreexplotadas según el balance hidrológico. Se exceptúan los aprovechamientos para abastecimiento de población, para aplicaciones de geotermia, para la reordenación de caudales sin aumento de volumen o para el mantenimiento y saneamiento de pozos y depósitos contra incendios. Por ello, en su conjunto, las medidas que prevé el Decreto consisten en reducir un $15 \%$ el volumen de extracciones, excepto en la agricultura, que desciende un $10 \%$, y en el abastecimiento a poblaciones, en las captaciones ligadas a la lucha contra incendios y en la geotermia, que no sufrirán restricciones.

Por otro lado, esta norma también recoge la suspensión de la tramitación y del otorgamiento de nuevas autorizaciones y concesiones de uso y la obligatoriedad de los suministradores (incluidos los de venta de agua en camiones) de utilizar agua desalada de octubre a abril. Los ayuntamientos estarán obligados a realizar estudios de detección de escapes y presentarlos a la Administración hidráulica en un plazo máximo de 45 días desde la entrada en vigor del Decreto, y a llevar a cabo un plan de actuación que tiene que validar la Dirección General de Recursos Hídricos en caso de que los escapes sean superiores al $25 \%$. Las obras necesarias para los cambios de uso se considerarán de utilidad pública y de necesidad urgente.

El período de aplicación y vigencia de este decreto se extenderá hasta que se haya superado el episodio de sequía. Es decir, cuando el índice publicado en el Portal del Agua presente valores de situación estable durante tres meses consecutivos. No obstante, algunas de las medidas deberían mantenerse como estructurales durante un dilatado período de tiempo a la vista del déficit hídrico de la isla. Igualmente, no se descartan nuevas medidas en la misma isla de Ibiza y en el resto del archipiélago. 


\section{Políticas de protección del medio marino}

\subsection{Aprobada la creación de la Reserva Marina del Freu de Sa Dragonera}

Una buena noticia, esperada por el sector pesquero y el de la conservación ambiental, ha sido la aprobación definitiva del acuerdo por el que se crea la Reserva Marina del Freu de Sa Dragonera y se procede a regular las actividades en esta área. Así, esta será la octava reserva marina del archipiélago, con 912 hectáreas que se suman a las 58.900 h ya declaradas en las islas. Por otro lado, la creación de esta nueva reserva responde a las peticiones de varios colectivos sociales e instituciones públicas como el Ayuntamiento de Andratx o el Parlament. Con el Decreto se limita la explotación de los recursos marinos vivos para incrementar la repoblación de alevines y proteger los ecosistemas.

El Decreto regula las actividades subacuáticas y de extracción de flora y fauna marinas en una zona con unos valores ecológicos y pesqueros considerables donde se puede encontrar una diversidad alta de hábitats y comunidades, tal como puso de manifiesto el estudio elaborado en el 2004 por el Consejo Superior de Investigaciones Científicas (CSIC) a propuesta de la Consejería de Medio Ambiente, Agricultura y Pesca.

En los paisajes submarinos de Sa Dragonera destacan las praderas de Posidonia oceanica, muy extendidas hacia el sur, que actúan como zonas de elevada producción biológica y de alevinaje de especies de interés pesquero. Ello conlleva que el área merezca un alto grado de protección. Asimismo, la zona incluye parte del Lugar de Importancia Comunitaria (LIC) de Sa Dragonera y forma parte del entorno marino del Parque Natural. En esta zona se llevan a cabo actividades que tienen una relación directa con los recursos pesqueros: la explotan de manera tradicional las embarcaciones profesionales de artes menores de Andratx y las embarcaciones recreativas de Sant Elm y el puerto de Andratx, y también se practica el buceo recreativo. Dado que varios informes del Servicio de Recursos Marinos han puesto de manifiesto que las poblaciones de peces vulnerables a la pesca se encuentran muy por debajo del nivel que potencialmente podrían presentar, es necesario regular las actividades para asegurar un mantenimiento compatible con la conservación de la riqueza biológica y de los recursos marinos vivos.

Entre otras medidas, el Decreto prohíbe en la zona los sistemas de pesca más agresivos como, por ejemplo, la pesca submarina, la de arrastre o la de cerco, y tan solo son autorizables las modalidades tradicionales de pesca profesional de artes menores y de pesca recreativa de superficie. Con relación a las modalidades de pesca y las actividades 
subacuáticas, la Consejería de Medio Ambiente, Agricultura y Pesca establecerá y delimitará las zonas y los usos (vedas, aparejos) permitidos en función de los resultados de seguimiento y los acuerdos que tome la Comisión de Seguimiento de esta reserva, creada por el artículo 8 del Decreto.

Igualmente, esta reserva marina se crea de acuerdo con la consideración de punto para la esperanza del mar Balear, declarado por el proyecto Mission Blue. El objetivo de la iniciativa es generar el apoyo de la sociedad para la protección de estos lugares mediante la creación de una red mundial de áreas marinas protegidas que salvaguarden el $20 \%$ de los océanos para el año 2020. El mar Balear es el único punto con esta consideración en el Mediterráneo.

Por otro lado, el Decreto contiene, además, una disposición adicional para ampliar la protección máxima de la Reserva Marina dels Freus de Ibiza y Formentera hasta la superficie inicial. El 22 de mayo de 2015 se modificaron los límites de la zona de protección máxima de S'Espardell, con lo que se redujo de manera relevante el área de la reserva integral sin que existiera ninguna justificación técnica o científica para ello. En este sentido, conviene ampliar de nuevo el área de protección máxima hasta las dimensiones originales para no dejar desprotegidas las comunidades de peces que se han desarrollado a raíz de la protección que se decretó en 1999. Así pues, se recupera la protección máxima de cien hectáreas que forman parte de las 15.000 que ocupa la Reserva Marina dels Freus de Ibiza y Formentera y que habían perdido la consideración de reserva integral.

Como dato final debe apuntarse que actualmente las Islas Baleares disponen de siete reservas marinas que ocupan una superficie total de 58.900 hectáreas y que son un elemento básico para la gestión pesquera, ya que se limita la explotación de los recursos marinos vivos para incrementar la repoblación de alevines y fomentar la proliferación de las especies marinas objeto de explotación o proteger los ecosistemas con características diferenciadas.

\subsection{En estudio la ampliación del Parque Nacional Marítimo-Terrestre del Archipiélago de Cabrera}

Respondiendo a una reclamación que comenzaba a ser histórica, se ha empezado a caminar con paso firme en la ampliación del Parque Nacional Marítimo-Terrestre del 
Archipiélago de Cabrera con la creación de una comisión específica el pasado 5 de julio. Esta comisión ha enfocado su trabajo a partir del resultado de los trabajos previos del equipo técnico del Parque que responden a peticiones realizadas desde organizaciones de conservación del medio ambiente en general y del marino en particular, como la organización Oceana. Tal como establecieron los acuerdos de gobernabilidad y como se acordó en el Consell de Govern, se ha aprobado la propuesta de ampliación del Parque. En los últimos meses se han realizado las tareas de recogida de información y se han iniciado los correspondientes contactos con los sectores para recoger las primeras impresiones sobre la propuesta.

Con esta nueva propuesta de ampliación se pretende proteger los entornos del archipiélago, que ahora están sometidos a una presión excesiva, crear un gran santuario de cetáceos en el sur e incorporar hábitats que no se encuentran en ningún otro parque nacional. Se debaten tres propuestas de ampliación: una de mínimos de 20.000 hectáreas; una de máximos de 90.000; y una intermedia que permita asegurar la gestión correcta del ámbito marino. En cualquier caso, la delimitación definitiva se realizará después de considerar toda la información recogida sobre los hábitats, las presiones y las amenazas potenciales. Debe tenerse presente que esta propuesta de ampliación de Cabrera afecta principalmente a aguas exteriores y, por lo tanto, de dominio estatal.

Las previsiones para materializar la ampliación propuesta implican elaborar en el plazo de un año el documento mencionado para que la Administración autonómica y la estatal lo aprueben. El proceso incluye una exposición pública de dos meses como método participativo que oriente la decisión final a adoptar en la aprobación definitiva.

Por otro lado, el Organismo Autónomo Parques Nacionales trabaja en nuevas propuestas de creación de parques nacionales como, por ejemplo, la de un parque exclusivamente marino en la isla de El Hierro, en el mar de Las Calmas. Asimismo, se trabaja en el Parque Natural Sierra de las Nieves, en Andalucía.

\subsection{El problema jurídico de las prospecciones en el Mediterráneo}

A. Comunicación a Bruselas de la inquietud por las prospecciones

Como hemos tratado en anteriores crónicas, en la agenda política de las Islas Baleares destaca como un asunto permanentemente pendiente la preocupación por los proyectos de prospección y sondeo en aguas del Mediterráneo cercanas al mar Balear. Estas 
concesiones plantean, además de un problema ambiental evidente, un problema jurídico y de conflicto entre el Estado y la Comunidad Autónoma dado que se autorizan en aguas pertenecientes al mar territorial (aguas exteriores). No obstante, ello no impide que el fuerte rechazo social que provocan las prospecciones conlleve también al rechazo del Govern, que ha trasladado su queja e inquietud a la Comisión Europea.

El Govern ha mantenido reuniones en Bruselas con el gabinete del comisario de Acción por el Clima y Energía, Miguel Arias Cañete, que se ha interesado por el estado de cada una de las tres iniciativas: la primera, la de Spectrum Geo Limited (Campaña sísmica 2D en las áreas libres del Mediterráneo norte occidental), promotora a la que el Ministerio de Agricultura, Alimentación y Medio Ambiente le ha otorgado una prórroga de nueve meses para que continúe la tramitación; la segunda es la de Schlumberger, que puede salir a exposición pública de impacto ambiental en cualquier momento; y la tercera es el proyecto de MedSalt2, del Instituto Nacional de Oceanografía y de Geofísica Experimental de Trieste (Italia), que busca encontrar grandes bancos de sal en el canal de Mallorca y al sureste de las Pitiüses mediante disparos realizados con cañones de aire comprimido.

Debe recordarse que estas tres iniciativas cuentan con la oposición de todo el arco parlamentario de las Islas Baleares y de los agentes sociales que se han manifestado en diferentes ocasiones. Las prospecciones son incompatibles con la propuesta de corredor migratorio de cetáceos situado entre las Islas Baleares y las costas de Cataluña y la Comunidad Valenciana, que se pretende que sea declarado zona especialmente protegida de importancia para el Mediterráneo (ZEPIM), propuesta que cuenta con el apoyo de la Dirección General de Medio Ambiente de la Comisión Europea y del Ministerio español y a la que dedicaremos una líneas en esta misma crónica.

El Govern ha transmitido al gabinete del comisario la queja que la Alianza Mar Blava envió a la Comisión Europea contra el Gobierno español, y que esta aceptó, en la que se criticaba que no se tuvieran en cuenta los efectos acumulativos de los proyectos de prospecciones de hidrocarburos en el Mediterráneo.

Esta negativa a las prospecciones implica buscar alternativas energéticas limpias. Por este motivo, el Govern asume que deben potenciarse las energías renovables, por lo que ha propuesto a Bruselas que, ahora que se discuten las directivas europeas en este ámbito, no penalice el autoconsumo ni la generación de energías renovables. Igualmente, se recuerda que deben establecerse primas diferenciadas para los territorios insulares, 
lugares con una problemática muy específica que también deben cumplir los objetivos para el 2020 (20-20-20), teniendo en cuenta que es más complicado implantar grandes infraestructuras rentables de este tipo en unas islas con un territorio limitado que en el continente.

\section{B. Archivo del procedimiento impulsado por Schlumberger}

Con posterioridad a lo explicado en el apartado anterior, se anunció que el Ministerio de Agricultura, Alimentación y Medio Ambiente procedería al archivo del proyecto de prospecciones de Schlumberger en el golfo de León, lo que se ha acogido muy favorablemente en el archipiélago. De hecho, tanto la Alianza Mar Blava como la Comisión de Medio Ambiente de las Islas Baleares habían pedido la caducidad y el archivo del expediente.

Así, se ha anunciado que el Ministerio de Agricultura, Alimentación y Medio Ambiente (MAGRAMA) ha archivado el proyecto "Campaña sísmica en áreas libres del golfo de León frente a las costas de Cataluña y las Islas Baleares", que impulsaba Schlumberger, después de que hayan transcurrido los tres meses que el MAGRAMA había otorgado el pasado mes de febrero al promotor para que aportara información adicional con el objetivo de poder formular la declaración de impacto ambiental del proyecto. La noticia se transmitió a través de la Alianza Mar Blava ya que el MAGRAMA no considera al ejecutivo autonómico parte interesada en la tramitación de estos expedientes, una decisión que recurrirá la Dirección General de Pesca y Medio Marino del Govern de les Illes Balears.

El proyecto "Campaña sísmica en áreas libres del golfo de León frente a las costas de Cataluña y las Islas Baleares” empezó en el 2011. Después de que la empresa impulsora, SeaBird Exploration, lo abandonara, tomó el relevo Schlumberger, que siguió tramitando el mismo expediente e inició uno nuevo en el 2014 con el mismo objetivo, si bien incumplió los trámites de exposición pública y de consultas. Después de reiteradas peticiones de la Alianza Mar Blava y de la Comisión de Medio Ambiente de las Islas Baleares (CMAIB), en febrero del año pasado el MAGRAMA anunció que archivaría el expediente de 2011 relativo al proyecto de prospecciones en el golfo de León y que iniciaría de nuevo la tramitación del de 2014, sacándolo a exposición pública y a consulta. En febrero de 2016 el MAGRAMA solicitó al promotor que aportara información 
adicional para poder formular la declaración de impacto ambiental del proyecto y le dio un plazo de tres meses para hacerlo. Por ello, pasado este período, la CMAIB, en el Pleno de 7 de julio, acordó instar al MAGRAMA a declarar la caducidad y el archivo del expediente, hecho que finalmente ha sucedido.

No obstante, todavía subsisten dos proyectos que afectan a las Islas Baleares: uno de prospección de hidrocarburos y otro de investigación para encontrar bancos de sal mediante cañones de aire comprimido. En el primer caso, en junio de 2016 el MAGRAMA otorgó una prórroga de nueve meses a Spectrum Geo Limited para que continuara la tramitación de su proyecto de prospecciones de hidrocarburos en el mar Balear, cuando el procedimiento ya había caducado después de haberse agotado el plazo de dieciocho meses, que acababa el 20 de abril, para realizar las tramitaciones ambientales correspondientes.

En el segundo caso, la CMAIB también ha pedido al MAGRAMA que el proyecto MedSalt2, del Instituto Nacional de Oceanografía y de Geofísica Experimental de Trieste (Italia), que busca encontrar grandes bancos de sal en el canal de Mallorca y al sureste de las Pitiüses mediante disparos de cañones de aire comprimido, pase una evaluación de impacto ambiental ordinaria y no simplificada en caso de que el proyecto no se archive directamente. En el mismo sentido se ha manifestado también la Alianza Mar Blava, que recuerda, además, que la confluencia de esta iniciativa y la de Spectrum en la misma región biogeográfica conlleva potenciales impactos acumulativos y sinérgicos que no se pueden obviar.

El acuerdo de archivo definitivo de la iniciativa de Schlumberger se publicó en el BOE (https://www.boe.es/diario_boe/txt.php?id=BOE-A-2016-9774).

\section{Políticas de protección de la diversidad biológica}

\subsection{Propuesta de creación del corredor de cetáceos del Mediterráneo}

En un apartado anterior se ha avanzado la existencia de una propuesta de corredor migratorio de cetáceos situado entre las Islas Baleares y las costas de Cataluña y la Comunidad Valenciana. Con esta iniciativa se pretende que este corredor sea declarado zona especialmente protegida de importancia para el Mediterráneo (ZEPIM). Cabe recordar que las ZEPIM son figuras de protección de carácter internacional declaradas a raíz de la firma del Protocolo sobre las zonas especialmente protegidas y la diversidad 
biológica del Mediterráneo (1995) en el marco del Convenio de Barcelona. Las ZEPIM son un conjunto de espacios costeros y marinos protegidos que garantizan la pervivencia de los valores y recursos biológicos del Mediterráneo; contienen ecosistemas típicos de la zona mediterránea o hábitats de especies en peligro, con un interés científico, estético o cultural especial.

Siguiendo con el trabajo para la declaración, se han mantenido contactos con las autoridades andaluzas, que ya en su día habían participado en un proyecto de declaración de una ZEPIM en el estrecho de Gibraltar y de un parque transcontinental entre España y Marruecos. Ahora, la Junta de Andalucía estudiará sumarse a la petición de la declaración del Corredor Migratorio de Cetáceos del Mediterráneo Occidental como ZEPIM en el marco del Convenio de Barcelona. La Junta de Andalucía ha acogido positivamente la iniciativa y estudiará la posibilidad de ampliarla para que proteja parte de la costa andaluza. Aunque actualmente no hay ningún proyecto de estudio o explotación de hidrocarburos que afecte a Andalucía, existe un especial interés en que se apruebe una propuesta que blinde la costa andaluza ante posibles futuros proyectos.

Todo apunta a que el Govern de les Illes Balears, en colaboración con la Alianza Mar Blava y los consejos insulares y los ayuntamientos, va a continuar con la estrategia de tejer alianzas con otras administraciones para conseguir el objetivo final de detener las prospecciones en las Islas Baleares y lograr un Mediterráneo libre de tales amenazas. A todo ello se suma el proyecto de ZEPIM del corredor de cetáceos que se promueve ahora.

\subsection{Programa de control de serpientes}

La conservación de la diversidad biológica y el mantenimiento de poblaciones de especies autóctonas en buen estado de viabilidad se están viendo amenazados por los fenómenos de la globalización y la introducción de especies invasoras de origen exótico. Estas especies suponen una grave amenaza para las poblaciones del archipiélago, que en algunos casos se ven seriamente comprometidas. En este contexto se ha iniciado en Ibiza un programa de control de serpientes con la instalación de 200 jaulas y el seguimiento de cómo incide la presencia de estos depredadores alóctonos en las poblaciones de lagartijas. Por su parte, el Consell Insular d'Eivissa instalará ciento cincuenta jaulas más en el marco de este programa compartido. 
Con este programa de control de serpientes en Ibiza, que impulsa el Govern con la colaboración del Consell Insular d'Eivissa, se persigue capturar las serpientes, pero también favorecer el conocimiento sobre la superficie invadida y el grado de invasión, reunir datos de las especies (ciclo biológico, alimentación, impactos potenciales...), potenciar la colaboración ciudadana y contribuir a la definición de las futuras actuaciones en relación con el problema de las serpientes invasoras desde la experiencia práctica.

Desde el año 2003 se produce la entrada accidental de ofidios peninsulares en las Islas Baleares. En Mallorca, donde ya había constancia de dos especies, se han detectado tres más, y en las Pitiüses, donde no había ninguna, se han detectado la serpiente de herradura (Hemorrhois hippocrepis) en Ibiza y la serpiente blanca o de escalera (Rhinechis scalaris) tanto en Ibiza como en Formentera. Esta llegada de ofidios a la Comunidad Autónoma se ha relacionado directamente con la introducción de olivos del sur de la Península en tráileres para usarlos en jardinería ornamental.

Es la primera vez que el Govern coloca trampas con este propósito en Ibiza, aunque el Consell Insular ya había puesto en marcha un programa piloto en los años 2014 y 2015. El año pasado se capturaron 121 serpientes, 117 de las cuales eran de herradura y 4 de escalera; se registró una media de 0,6 capturas por trampa y día en los 19.419 trampeos que se realizaron.

La iniciativa de la Consejería empezó el 28 de mayo con la instalación de las primeras trampas y desde el 20 de junio cuenta con una veterinaria del Consorcio para la Recuperación de la Fauna de las Illes Balears (COFIB) destinada solo a este proyecto, que dispondrá de un vehículo y un espacio de trabajo en las instalaciones del Institut Balear de la Natura (IBANAT) en Sa Coma. El programa piloto en las Pitiüses también recoge las actuaciones en Formentera, donde se han instalado 69 de las 100 trampas previstas, que en 1.787 trampeos han capturado 191 ejemplares, mientras que en Ibiza se han colocado 40 trampas, en las cuales han caído 45 serpientes tras 378 trampeos. El 44\% de las serpientes capturadas en Formentera se han alimentado de lagartijas.

Asimismo, se está elaborando un estudio vinculado al programa para conocer de qué se alimentan los ofidios capturados. Este estudio, elaborado por la Universitat de les Illes Balears (UIB), demuestra que el $44 \%$ de las serpientes que se han capturado tenían lagartijas en el estómago, el 65\% algún roedor y el 14\% habían ingerido tanto lagartijas como roedores. 
Como acción complementaria, el Govern trabaja en un acuerdo inicial con el Ministerio de Agricultura, Alimentación y Medio Ambiente y el Gobierno de Canarias para sacar adelante una estrategia de gestión de las serpientes invasoras en ecosistemas insulares, además de negociar una moratoria de importación de árboles ornamentales hasta que se apruebe dicha estrategia.

\subsection{Programa de control de la avispa asiática}

Otra de las campañas que se llevan a cabo en las islas, más concretamente en Mallorca, es la del control de la avispa asiática, que se está convirtiendo en un grave problema en otras comunidades autónomas que amenaza la supervivencia de las abejas y de la apicultura. La avispa asiática es una especie exótica invasora que depreda activamente a polinizadores como la abeja de la miel y que causa graves perjuicios al sector apícola y a los ecosistemas naturales. La avispa asiática, Avispa velutina, es un himenóptero exótico, catalogado como invasor, que provoca daños graves a las colonias de abejas (de las cuales es un activo depredador), destruye muchos otros insectos útiles y puede suponer un cierto riesgo para las personas por el tamaño de su aguijón, aunque no es especialmente agresiva. El año pasado la Consejería de Medio Ambiente, Agricultura y Pesca retiró un nido de avispa asiática el mes de noviembre en la zona del Mirador de Ses Barques (Sóller), y se eliminaron todos los individuos de la colonia. El nido, de forma semiesférica, pesaba unos ocho kg y medía setenta $\mathrm{cm}$ de altura. Más recientemente se localizó un nuevo nido también en el término municipal de Sóller. En estos momentos, la Consejería de Medio Ambiente, Agricultura y Pesca, el Laboratorio de Zoología de la UIB, el Ayuntamiento de Sóller y el COFIB han iniciado las tareas de detección de nuevas colonias con el objetivo de eliminarlas siguiendo un protocolo establecido.

El día 14 de julio de 2016 se detectó una avispa viva cerca de Sóller por parte de un particular. Inmediatamente se puso en marcha un operativo para descubrir su origen en el que participaron el COFIB, técnicos del Servicio de Especies, agentes de Medio Ambiente, especialistas de la UIB y personal del Ayuntamiento de Sóller. La detección de un nido es una tarea muy difícil ya que las avispas se desplazan varios quilómetros para alimentarse. Se han hecho pruebas, sin éxito, para colocar emisores de seguimiento de 0,42 $\mathrm{g}$ en algunos animales, pero finalmente ha sido el seguimiento visual de los animales lo que ha permitido localizar el nido en la zona más alta de un pino, a unos diez 
metros de altura. Descartadas otras opciones, se consideró que la mejor era la retirada manual por parte de especialistas del COFIB con equipamiento específico para esta tarea y con apoyo del Cuerpo de Agentes de Medio Ambiente. La operación se realizó durante la noche para garantizar la recogida de todo el enjambre, que posteriormente fue sometido a congelación para sacrificar toda la colonia y seguir con la investigación.

Hay que tener presente que las colonias están formadas por unos dos mil ejemplares y producen unas ciento cincuenta hembras fértiles por temporada, que suelen dar lugar a seis nidos nuevos cada año. La progresión, si las colonias no se destruyen en los primeros estadios, puede ser muy rápida. Actualmente la avispa asiática ha ocupado de forma masiva buena parte de Europa occidental y, en el Estado español, toda la cornisa cantábrica peninsular y el norte de Cataluña, donde las medidas de control se limitan a las zonas habitadas.

Por ahora parece que se está consiguiendo controlar la presencia de la avispa asiática, con el balance de siete nidos de Avispa velutina capturados desde el año 2015, la mayor parte de ellos ubicados en el valle de Sóller. El primer nido se localizó en octubre de 2015 y durante el 2016 se han capturado seis nidos más, siete en total. Un rasgo que caracteriza todos los nidos es que se han encontrado en el valle de Sóller en un radio de un máximo de diez km de longitud y casi siempre en árboles de hoja perenne como pinos, encinas o cipreses.

El seguimiento principal lo realiza el Cuerpo de Agentes de Medio Ambiente y para facilitar la colaboración ciudadana se utiliza una aplicación móvil, la VespApp, y la página web vespapp.uib.es.

\subsection{Programa de potenciación de la posidonia y de control de especies invasoras}

Las Islas Baleares se hallan en una zona climática óptima para la conservación de la posidonia, lo que comporta una responsabilidad con vistas a su conservación y al control de las especies invasoras que puedan comprometer la evolución de las praderas de esta planta. Por este motivo, las Islas Baleares, tras lograr una postura común de las comunidades autónomas, han situado las especies invasoras y la conservación de la posidonia en la agenda europea al introducir ambas preocupaciones en el orden del día del Consejo de Ministros de Medio Ambiente de la Unión Europea. Así, en el orden del día del último consejo se incorporaron una iniciativa legislativa relativa a la propuesta de 
revisión de los sectores no sujetos al régimen de comercio de derechos de emisión (ETS) y dos no legislativas: los proyectos de conclusiones del Consejo sobre el Convenio sobre la Biodiversidad Biológica y sobre la gestión sostenible del agua.

En estos puntos, las Islas Baleares han conseguido una postura común de todas las comunidades que también tiene en cuenta la idiosincrasia del archipiélago. Así, en el marco del Convenio sobre la Diversidad Biológica (CDB) se ha tratado sobre la afectación de los ruidos en el mar y la incidencia en este ámbito de los microplásticos y de la contaminación, que provocan la pérdida de biodiversidad marina y costera. Por otro lado, en este mismo documento se ha introducido como prioritaria la cuestión de las especies invasoras para poder controlar las vías de entrada de esta afectación ambiental.

\section{Conservación in situ en espacios naturales}

\subsection{La zona de Son Bosc se reincorporará al Parque Natural de S'Albufera}

En uno de los primeros números de la RCDA se trató el problema de la retirada de la zona de Son Bosc del Parque Natural de S'Albufera de Mallorca. Igualmente, en números más recientes se han tratado la problemática jurídica de esta retirada y las sentencias que han ido recayendo en los sucesivos pleitos interpuestos. Gracias a la acción ciudadana e institucional —esta última durante algunos períodos legislativos-, Son Bosc volverá a formar parte del Parque Natural de S'Albufera de Mallorca. Así, aprovechando la tramitación de la Ley 12/2016 (que hemos comentado al inicio de esta crónica), se ha propiciado la ampliación del Parque al derogar, por medio de la LEA, la normativa que tenía como único objeto sacar esa zona del Parque. De esta forma, Son Bosc volverá a formar parte del Parque Natural de S'Albufera de Mallorca después de que el Parlament aprobara la Ley de Evaluación de Impacto Ambiental, que incluyó una disposición derogatoria de la norma que tenía como único objeto construir un campo de golf en esta finca. Se cumplen así las recomendaciones de la Misión de Asesoramiento del Convenio de Ramsar de 25 de febrero de 2011, que lo proponía explícitamente, y también las diferentes sentencias que habían cuestionado la constitucionalidad de la normativa anterior.

La Ley 9/2010, de 27 de julio, de declaración de interés autonómico de la construcción del campo de golf de Son Bosc, derogaba un acuerdo del Consell de Govern de inicio del procedimiento de elaboración del Plan de Ordenación de los Recursos Naturales (PORN) 
de S'Albufera y lo hacía respecto de una finca registral concreta, lo que representaba un ejemplo de legislación a la carta realmente denunciable.

El Comité Ramsar indicó en su día que la zona de Son Bosc era una parte integral e inseparable del ecosistema de S'Albufera y recomendó “ampliar los límites del lugar Ramsar para incluir Son Bosc y recoger la posibilidad de que la ampliación se incluya dentro del Parque Natural de S'Albufera de Mallorca”. En la misma línea, apuntaba que “el nuevo PORN que se tendrá que aprobar para S'Albufera tendría que incluir la zona de Son Bosc, específicamente excluida del inicio de PORN actual por la Ley 9/2010”.

Esta incorporación cumple así las recomendaciones de Ramsar respecto de la zona húmeda de importancia internacional de S'Albufera de Mallorca, atendiendo también a las consideraciones del Tribunal Superior de Justicia de las Islas Baleares. Ya en la legislatura 2007-2011 se promovió la ampliación de la Zona de Especial Protección para las Aves (ZEPA) de S'Albufera de Mallorca, que se adoptó por medio de un acuerdo del Consell de Govern el 25 de febrero de 2011, una decisión basada en informes técnicos reiterados sobre la importancia de la zona de Son Bosc por la existencia de aves que figuran en el anexo I de la Directiva de Aves.

Por eso, la aprobación de la Ley de Evaluación de Impacto Ambiental representa también el visto bueno a la revisión del PORN del Parque Natural de S'Albufera, que como mínimo se ampliará hasta Son Bosc, lo que supondrá añadir 10 hectáreas a las 1.646,48 existentes.

\subsection{Introducción del milano real en el Parque Natural de Mondragó}

Una de las aplicaciones prácticas de la implantación de espacios naturales protegidos y de sus instrumentos de ordenación se manifiesta en los programas de conservación in situ mediante programas de introducción de especies que se habían visto desplazadas. Esta primavera ha nacido el primer polluelo de milano real (Milvus milvus) en el Parque Natural de Mondragó desde que se declaró espacio natural protegido en 1992. Se trata de una pareja que el año pasado ya había nidificado pero que no había conseguido criar, lo que representa un éxito en los objetivos de conservación de este espacio protegido.

Con la colaboración del Grup Balear d'Ornitologia i Defensa de la Naturalesa (GOB) y del Servicio de Agentes de Medio Ambiente, y con el apoyo material de Endesa, el polluelo ha sido anillado (con marca de lectura a distancia) y equipado con un emisor de 
seguimiento por satélite que permitirá realizar la monitorización y obtener información sobre el uso que haga del territorio.

El milano real fue declarado especie en peligro de extinción en el año 2003, por lo que la Consejería de Medio Ambiente, Agricultura y Pesca redactó y aprobó en el año 2008 un plan de recuperación que perseguía el objetivo de recuperar las poblaciones de esta especie en las Islas Baleares hasta situarlas fuera de peligro, reduciendo la mortalidad, tanto adulta como inmadura, y asegurando superficies extensas de hábitats de calidad.

El milano real había sido una especie muy común en toda la isla de Mallorca, pero en las últimas décadas la población de esta ave había sufrido un grave descenso provocado por motivos diversos como son la desaparición de hábitats adecuados, la electrocución en líneas eléctricas y, sobre todo, el envenenamiento. Actualmente en las Islas Baleares hay unas cien parejas reproductoras. El grueso de la población de milano real se concentra principalmente en la sierra de Tramuntana. El nido de Mondragó es el único conocido en la zona del sureste de Mallorca, hecho por el cual reviste especial interés.

El objetivo principal de un parque natural es la conservación de la biodiversidad. Por ello, la cría del milano real en Mondragó representa uno de los mejores beneficios que se pueden esperar de un espacio natural protegido: contribuir a la recuperación de especies en peligro de extinción.

\subsection{Cría del ibis negro en el Parque Natural de S'Albufera de Mallorca}

En la misma línea que la noticia anterior, cabe destacar que el ibis negro ha criado por primera vez en S'Albufera de Mallorca; de hecho, que se tenga constancia, es la primera vez que se documenta un caso en las Islas Baleares. Desde hace años en el Parque Natural de S'Albufera de Mallorca varias especies de garzas crían conjuntamente en un pequeño tramo de bosque de ribera y forman una impresionante colonia reproductora mixta, con decenas de parejas de garceta común (Egretta garzetta), garcilla bueyera (Bubulcus ibis), martinete común (Nycticorax nycticorax) y garcilla cangrejera (Ardeola ralloides). Todas estas especies han colonizado las Islas Baleares como reproductoras gracias precisamente al establecimiento de esta colonia. Este año, una nueva especie, la quinta que se documenta, se ha sumado a las cuatro que ya criaban. No ha sido una garza, sino una especie de ibis, el ibis negro o morito común (Plegadis falcinellus). El ibis negro es la única especie de su familia nativa del continente europeo, donde es escasa. Está 
catalogada "de interés especial" y en el Libro Rojo de las Aves de España se considera una especie vulnerable. En S'Albufera se han encontrado estos días dos nidos con polluelos, y se sospecha de la presencia de uno o dos nidos más.

\section{Políticas sobre los recursos hídricos}

En relación con la crónica relativa a la aprobación del Decreto de Sequía en Ibiza, podemos completar la noticia con el relato de una serie de medidas complementarias destinadas a fomentar el ahorro de agua en el archipiélago, en este caso mediante una campaña de concienciación en los establecimientos hoteleros.

Así, en el marco de esta campaña de sensibilización se han editado 51.500 carteles para ser colocados en los pomos de las puertas — 25.750 en inglés y la otra mitad en alemáncon el lema: "El agua es un bien escaso. ¡Piensa!”. El cartel, que será colocado en las puertas de los sanitarios y de las cocinas, explica consejos de buenas prácticas para ahorrar agua en apartamentos, hoteles y otras instalaciones de restauración.

Con este material se invita a los turistas a participar en la campaña de difusión y concienciación para un uso racional del agua. Dicha campaña tiene una imagen propia en diferentes formatos y estilos, y busca destacar el momento actual de prealerta por sequía y sensibilizar a la población y a los visitantes, especialmente durante la temporada turística, de máxima presión sobre este recurso. Esta acción se suma a otras iniciativas que se han llevado a cabo en el marco de la campaña de concienciación de ahorro de agua, que empezó con un spot que se ha convertido en viral en las redes sociales.

Puede accederse a la campaña desde este enlace publicado en la web del Govern: http://www.caib.es/govern/sac/fitxa.do?codi=2608586\&coduo=138143\&lang=ca

\section{Política de residuos}

La gestión de residuos en Baleares varía según la isla. La competencia de los residuos no peligrosos corresponde a los consejos insulares, mientras que la gestión y el tratamiento de los peligrosos depende del Govern. Con todo, en las cuatro islas la gestión de los residuos plantea serios problemas derivados del hecho insular y de una gestión histórica deficiente. Una anomalía que comentaremos a continuación se pone de manifiesto en relación con el tratamiento de los residuos de envases, que dispone de una comisión de 
seguimiento con el gestor ECOEMBES que no se reunía desde 2011. Esta comisión deriva del Convenio Marco suscrito en su día y su operatividad había quedado seriamente cuestionada.

Esta comisión está integrada por el Govern, los consejos insulares, EMAYA (empresa de residuos de Palma de Mallorca) y la FELIB (Federació d'Entitats Locals de les Illes Balears), además de ECOEMBES. Con este órgano se buscan dos objetivos: cumplir el convenio firmado, que obliga a crear una comisión que realice el seguimiento y facilite todos los datos de que se disponga — en este caso, de la recogida de envases ligeros y de papel y cartón-, y aprovechar el espacio para compartir experiencias y resolver problemas.

La convocatoria de la Comisión de Seguimiento del Convenio Marco con ECOEMBES tuvo lugar después de cuatro años sin realizarse. En este contexto, el Govern ha restablecido los contactos con cerca de veinte sistemas colectivos de responsabilidad ampliada del productor que trabajan en las Islas Baleares para poner en marcha campañas de comunicación, sensibilización y buenas prácticas, con lo que se recupera una relación directa que se había perdido y se ofrece la colaboración del ejecutivo autonómico. En este ámbito se están revisando acciones y convenios como el de Ecovidrio; se han mantenido reuniones con Ambilamp para reforzar la implantación de puntos de recogida de luminaria fluorescente; y se negocia una campaña en talleres mecánicos con Sigaus (entidad que gestiona el aceite industrial usado, como el de los coches). Aparte, están en marcha las campañas de SIGRE, para la recogida de medicamentos caducados, y de Ecopilas.

En la Comunidad Autónoma están autorizados cerca de una veintena de sistemas colectivos de responsabilidad ampliada gestionados por entidades sin ánimo de lucro que se responsabilizan de la gestión correcta de los residuos que se generan al final de la vida útil de los productos que se ponen en el mercado: envases ligeros, de vidrio y de papel o cartón, pilas y acumuladores, neumáticos fuera de uso, aceites industriales usados, envases de medicamentos y medicamentos caducados, envases de productos fitosanitarios y residuos de aparatos eléctricos y electrónicos. 


\section{Sobre la aplicación del impuesto del turismo sostenible}

Uno de los proyectos legislativos estrella del actual Govern ha sido la aprobación de la Ley $2 / 2016$, de 30 de marzo, del impuesto sobre estancias turísticas en las Illes Balears y de medidas de impulso del turismo sostenible. Una de las acciones de gestión del impuesto implica decidir su destino finalista. Por ello, el Govern, a través de la Consejería de Medio Ambiente, Agricultura y Pesca, prepara proyectos de medio rural que se puedan beneficiar de este impuesto. Como primera medida se está trabajando en el denominado contrato agrario, una de las demandas de la organización agraria Unió de Pagesos, destinado a las explotaciones más clásicas y familiares con policultivos (como rebaños, cereales y hortalizas), que normalmente quedan al margen de las líneas de ayuda ordinarias.

Probablemente, desde una perspectiva de preservación del paisaje agrícola, este destino sea una buena aportación del impuesto, junto con una mejor dotación de los recursos destinados a la protección y gestión de los espacios naturales protegidos y los recursos naturales más vulnerables como el agua. 
Sumari: 1. Introducció. 2. Activitat legislativa. 2.1. Aprovació de la Llei 12/2016, de 17 d'agost, d'avaluació ambiental de les Illes Balears. 2.2. Tramitació del Projecte de llei de declaració del Parc Natural d'es Trenc-es Salobrar. 2.3. Aprovació d'un decret de sequera a Eivissa. 3. Polítiques de protecció del medi marí. 3.1. Aprovada la creació de la Reserva Marina del Freu de sa Dragonera 3.2. L'ampliació del Parc Nacional Maritimoterrestre de l'Arxipèlag de Cabrera en estudi. 3.3. El problema jurídic de les prospeccions al Mediterrani. 4. Polítiques de protecció de la diversitat biològica. 4.1. Proposta de creació del corredor de cetacis del Mediterrani. 4.2. Programa de control de serps. 4.3. Programa de control de la vespa asiàtica. 4.4. Programa de potenciació de la posidònia i de control d'espècies invasores. 5. Conservació in situ en espais naturals. 5.1. La zona de Son Bosc es reincorporarà al Parc Natural de s'Albufera. 5.2. Introducció del milà reial al Parc Natural de Mondragó. 5.3. Cria de l'ibis negre al Parc Natural de s'Albufera de Mallorca. 6. Polítiques sobre els recursos hídrics. 7. Política de residus. 8. Sobre l'aplicació de l'impost de turisme sostenible.

\section{Introducció}

Si es pot destacar un aspecte en aquesta nova etapa que va començar amb la IX legislatura, és l'amplitud de les polítiques ambientals i el seu increment de protagonisme en l'agenda política. Com a contrapunt, podríem plantejar la lentitud en l'adopció de determinades mesures que fa anys que conformen una reivindicació constant entre el moviment ecologista i de protecció ambiental de l'arxipèlag.

És evident que el panorama va millorant i que s'han adoptat normatives molt importants encaminades a revertir un procés de "barra lliure" (disculpeu l'expressió) que es va configurar en la legislatura anterior, en la qual el medi ambient va ser marginat a favor del creixement econòmic a qualsevol preu, especialment a costa de penalitzar la conservació i d'implantar una permissivitat que, a més d'atemptar contra tota lògica ambiental, no va servir per diversificar la vulnerable economia illenca que descansa gairebé exclusivament en el monocultiu turístic.

En la crònica d'aquest semestre no abunden les novetats legislatives, atès que les primeres mesures van ser un fre als excessos de la legislatura anterior, i l'activitat parlamentària d'aquest semestre ha prioritzat les polítiques socials per sobre de les ambientals. No obstant això, podem destacar l'aprovació de la llei autonòmica d'avaluació ambiental, pendent des del 2013, que ha optat per reconèixer la utilitat procedimental de la legislació bàsica estatal i s'ha limitat a perfilar les especificitats derivades de la condició ambiental especial del nostre arxipèlag.

La resta de novetats normatives és inexistent. Solament podem destacar instruments normatius en tramitació o normes de caràcter menor. En qualsevol cas, el més destacable és l'avenç en la tramitació de la llei que ha d'aprovar la creació del Parc Natural d'es Trenc - es Salobrar, un deute històric pendent amb el conservacionisme balear (i més 
concretament amb el mallorquí), i l'adopció de mesures extraordinàries a Eivissa a causa de la sequera que afecta aquesta illa.

Quant a l'aplicació de polítiques de gestió, la crònica és més abundant. El recorregut que farem comprèn polítiques de protecció del medi marí, amb la creació de noves reserves i la important ampliació del Parc Nacional de l'Arxipèlag de Cabrera, o les propostes de cessament d'activitats pernicioses al Mediterrani o la creació d'un corredor de cetacis.

Les polítiques de conservació de la diversitat biològica, en aplicació dels compromisos internacionals adoptats, també avancen, encara que la lluita s'està centrant en els efectes de la globalització que conflueixen en la introducció d'espècies invasores d'origen exòtic.

Finalment podrem analitzar algunes iniciatives que justifiquen la importància de la gestió dels parcs naturals com a eines de conservació in situ molt efectives per a la recuperació d'espècies i com a aportació a la millora de la diversitat biològica. També proposem alguna notícia pel que fa a residus, aigua o conservació a partir de la recaptació de l'impost del turisme sostenible o "ecotaxa".

\section{Activitat legislativa}

\subsection{Aprovació de la Llei 12/2016, de 17 d'agost, d'avaluació ambiental de les Illes}

\section{Balears}

Amb algun retard respecte a les previsions que emanen de la Llei 21/2013, de 9 de desembre, d'avaluació ambiental (LAA), aprovada per les Corts Generals i publicada en el Butlletí Oficial de l'Estat número 296, d'11 de desembre de 2013, la Comunitat Autònoma de les Illes Balears ha adoptat una llei pròpia d'avaluació ambiental adaptada al text bàsic estatal que assumeix en la seva majoria, en què el Parlament balear adopta una llei d'especificitat procedimental i de supòsits afegits adaptats a la realitat insular. Aquesta nova llei també incorpora els principis de transparència de l'actuació administrativa i modernització de l'Administració amb l'impuls de la tramitació electrònica.

Així, la Llei 12/2016, de 17 d'agost, deroga i substitueix el text de la Llei 11/2006 i intenta oferir més seguretat jurídica i simplificar els procediments adaptats a les previsions estatals. La nova LAA balear es configura com un instrument fonamental per a la protecció del medi ambient, el benestar ciutadà i la salut, de manera compatible amb el 
desenvolupament econòmic i social de l'arxipèlag, tenint en compte les peculiaritats d'un sistema insular sensible i limitat, tot i que d'una lectura detinguda del nou text autonòmic podem desprendre que s'adopta gairebé íntegrament el procediment implantat en la legislació bàsica estatal. Aquest canvi legislatiu està motivat per l'obligació d'adaptar-se a l'assenyalada legislació estatal modificada el 2013, amb més incidència en la concepció dels processos participatius, la transparència i la simplificació de determinats tràmits. El nou marc d'avaluació ambiental considera que la informació pública no és únicament un tràmit sinó un aspecte essencial, per aquest motiu s'incorporen els mitjans electrònics com a forma habitual de comunicació, a la qual cosa cal afegir que els projectes s'han de publicar íntegrament al web corporatiu per a general coneixement.

Igualment, en la mesura que permeten la regulació bàsica i la complexitat de la matèria, la Llei 12/2016 procura simplificar la tramitació sense perdre el rigor i l'exigència en la preservació ambiental, per exemple excloent una sèrie d'obres de l'autorització administrativa preceptiva que ha d'emetre l'Administració hidràulica quan concerneixin actuacions menors. També se simplifica la tramitació dels projectes que afecten la Xarxa Natura 2000 en els casos en què no repercuteixin de manera apreciable sobre els espais. I és que la Llei 21/2013 preveu que els plans, els programes i els projectes que, sense tenir relació directa amb la gestió d'un lloc Xarxa Natura 2000 o sense ser necessaris per a aquesta gestió, puguin afectar de manera apreciable aquests llocs o espais, ja sigui individualment o en combinació amb altres plans, programes o projectes, s'han d'avaluar amb els procediments que preveu la legislació estatal. Per aquest motiu, la Llei 12/2016 dedica el títol IV a l'avaluació de repercussions als espais Xarxa Natura 2000, amb les especificitats esmentades.

D'altra banda, també ha calgut adaptar la Llei 5/2005 (LECO) a la nova normativa europea i estatal bàsica, per la qual cosa la disposició final segona d'aquesta llei modifica l'article 39 de la LECO, per regular el procediment de repercussions. Igualment, la disposició final segona modifica la LECO, i actualitza les regulacions d'ús públic dels espais de rellevància ambiental, i procura fer-los compatibles amb l'accés al medi natural, en concret de l'ús de camins existents per accedir a la costa. La Llei compleix també un acord unànime del Parlament de les Illes Balears sobre la necessitat de regular i controlar l'activitat coneguda com a party-boats, una moda en alça que comença a plantejar alguns impactes ambientals importants, especialment en zones biològicament sensibles. En el mateix sentit, s'ha aprofitat per facultar el Consell de Govern de la Comunitat Autònoma 
per protegir espais sense haver de comptar amb el vistiplau del $50 \%$ dels propietaris de l'àrea que s'ha de protegir.

D'altra banda, és destacable la previsió que fa la Llei 12/2016 en obligar l'Estat a consultar a l'òrgan ambiental, la Comissió de Medi Ambient de les Illes Balears, quan els projectes que avaluï afectin la comunitat autònoma. Així, es preveu expressament que la CMAIB emeti un informe preceptiu.

Quant a la democratització i transparència dels procediments d'avaluació ambiental, un dels elements més segurs per mesurar la qualitat d'una democràcia és la transparència informativa; així ho entén la Unió Europea, que en la Carta dels drets fonamentals (Tractat de Lisboa) inclou el dret d'accés als documents (article 42), desplegat en la Directiva 2003/98/CE del Parlament europeu i del Consell, de 17 de novembre de 2003, relativa a la reutilització de la informació del sector públic, modificada per la Directiva 2013/37/UE del Parlament europeu i del Consell, de 26 de juny de 2013. El Conveni 205 del Consell d'Europa, sobre accés a documents públics, de 2009, malgrat no ha estat ratificat per Espanya, ha esdevingut una fita en la regulació de la transparència i es reconeixen les traces en la Llei 19/2013, de 9 de desembre, de transparència, accés a la informació pública i bon govern. En aquesta mateixa línia, la nova LAA autonòmica aprofundeix en la utilització de mitjans electrònics com a manera habitual de comunicació, per facilitar la participació, la transparència i l'accés a la informació, en la línia de la legislació bàsica sobre el procediment administratiu i de la Llei 11/2007, de 22 de juny, d'accés electrònic dels ciutadans als serveis públics. No obstant això, sobre aquesta matèria encara queda molt recorregut per fer, donat el retard en la implantació de l’Administració electrònica que s'arrossega.

En la mesura que ho permeten la regulació bàsica i la complexitat de la matèria, també procura simplificar la tramitació sense perdre el rigor i l'exigència en la preservació ambiental, tant en el procediment d'avaluació ambiental mateix com en el de repercussions de la Llei 5/2005. En aquesta mateixa línia, la disposició final tercera exclou de l'autorització administrativa preceptiva de l'Administració hidràulica una sèrie d'obres i actuacions menors.

En general, es planteja la legislació autonòmica com un apèndix de la Llei 21/2013, que passa a ser una norma d'aplicació directa. Així, s'ha descartat l'opció de transcriure-la íntegrament com semblava que era la intenció d'algunes comunitats autònomes, i s'ha preferit circumscriure la regulació autonòmica al desplegament normatiu de les 
especificitats en les Illes Balears, excepte quan s'ha considerat que era més pràctic i clar refondre la regulació de la llei bàsica amb les especificitats de la normativa de les Illes Balears.

La llei consta de sis títols, amb el preliminar inclòs, una disposició addicional, una disposició transitòria, una disposició derogatòria, vuit disposicions finals i quatre annexos. El títol preliminar, a més d'establir l'objecte i l'abast de la llei, també recull, en les finalitats de la norma, els principis de dret internacional, europeu i de la legislació bàsica, perquè s'ha considerat oportú reproduir-los a l'inici de la llei, junt amb els principis de cooperació interadministrativa. Així mateix, tal com hem apuntat, regula el compromís amb la participació, la transparència i l'Administració electrònica, i el conflicte entre la publicitat i la confidencialitat de les dades.

El títol I confirma la Comissió de Medi Ambient de les Illes Balears com l'òrgan ambiental de les Illes Balears, precisa l'estructura en òrgans i introdueix la novetat del caràcter públic de les sessions del Ple.

El títol II regula estrictament els procediments d'avaluació ambiental. En desplegament de la normativa bàsica, i per evitar procediments innecessaris, la Llei s'acull a l'article 3.5 de la Directiva 2001/42/CE per establir quins plans o modificacions no tenen efectes significatius en el medi ambient, o entén que hi seran favorables, i que, per tant, no estan subjectes als procediments d'avaluació ambiental estratègica, excepcions recollides en la derogada Llei 11/2006.

En la documentació dels estudis d'impacte ambiental s'ha inclòs, a més del contingut mínim que estableix la llei bàsica, un annex d’incidència paisatgística, que té present tant l'actiu que representa el paisatge en les Illes Balears com la vigència del Conveni europeu del paisatge, aprovat pel Consell d'Europa el 20 d'octubre de 2000, que va entrar en vigor a l'Estat espanyol l'1 de març de 2008.

El títol III regula de manera específica la consulta preceptiva a l'òrgan ambiental de la comunitat autònoma pel que fa als plans, els programes i els projectes que ha d'avaluar l’Administració General de l'Estat.

El títol IV tracta sobre l'avaluació de les repercussions als espais Xarxa Natura 2000, en la línia exposada. 
Finalment, el títol V regula matèries cabdals en l'avaluació ambiental però que sovint són negligides en la pràctica, el seguiment dels procediments ambientals, la protecció de la legalitat ambiental, el restabliment de l'ordre jurídic pertorbat i el règim sancionador.

\subsection{Tramitació del Projecte de llei de declaració del Parc Natural d'es Trenc-es} Salobrar

Ja havíem tractat en una crònica anterior el procés d'elaboració d'un projecte de llei de declaració d'un espai natural històric i emblemàtic de Mallorca. Així, vam retre comptes de les característiques i vicissituds de l'Avantprojecte de llei de declaració del Parc Natural d'es Trenc - es Salobrar de Campos, projecte normatiu i de declaració singular que se sotmet ara a un segon període d'exposició pública, del qual no en tenim resultat al tancament d'aquesta crònica. De fet, el Govern va iniciar aquest tràmit de forma voluntària, conferint un mes als possibles interessats com a conseqüència de la modificació substancial del text inicial arran de les 97 al·legacions rebudes en el primer període d'exposició pública. Aquest nou avantprojecte de llei de declaració del Parc Natural d'es Trenc - es Salobrar de Campos, ha estat publicat en el Butlletí Oficial de les Illes Balears (BOIB) després que el text sofrís una modificació substancial que feia recomanable exposar-lo novament a la llum pública.

Aquesta segona exposició pública ha tingut una durada d'un mes amb l'objectiu de donar un valor afegit al procés participatiu de l'elaboració de la Llei. En aquest sentit, no només es va publicar i es va difondre la iniciativa pel BOIB, sinó que l'avantprojecte es va publicar també a la pàgina web de la Conselleria de Medi Ambient, Agricultura i Pesca (http://maap.caib.es) i a la de la Direcció General de Participació i Transparència (http://participaciociutadana.caib.es).

Analitzats els dos textos, l'inicial i el segon avantprojecte exposat al públic, les principals novetats de l'esborrany són les següents:

Es modifiquen els límits per deixar fora de la zona d'influència el Club Nàutic de sa Ràpita, a petició dels concessionaris del port i de Ports de les Illes Balears; s'afegeixen com a activitat prohibida les esteses elèctriques i el vol amb motor a baixa altura a petició del Grup Ornitològic Balear (GOB); s'especifica més detalladament el contingut del Pla d'Ordenació de Recursos Naturals (PORN), la qual cosa ofereix més cobertura al règim 
del parc natural; s’implanta un nou article sobre la restauració ambiental de les zones degradades que existeixen a la zona.

D’altra banda, en relació amb la creació de la Junta Assessora del Parc, el gran interès que ha despertat i el fet que nombroses organitzacions van expressar la voluntat de tenir representació, s'ha respectat la composició proposada inicialment, ja que es tracta d'un òrgan consultiu i transitori fins a l'aprovació d'una reglamentació pròpia.

El nou esborrany modifica la disposició addicional i es canvia la nomenclatura d'accessos per itineraris. Respecte de la xifra d'1.500 vehicles, es matisa que és de forma transitòria fins a l'aprovació del PORN, eina d'ordenació que ha d'establir un nombre definitiu i la ubicació de les infraestructures necessàries. En aquesta mateixa línia es va acceptar l'al-legació de l'Ajuntament de Campos per incloure expressament una referència en la Llei en relació amb el fet que els beneficis generats en la gestió dels equipaments d'aparcament revertiran en la conservació de l'espai.

D'altra banda, el nou text elimina les disposicions finals primera i segona de modificació de les DOT (directrius d'ordenació del territori) i de la LECO (Llei per a la conservació d'espais de rellevància ambiental) en vista al fet que es tracta d'una llei singular i la modificació que es proposava en tals disposicions era més pròpia d'una llei general. Aquesta supressió es va dur a terme a suggeriment de l'advocacia de la Comunitat Autònoma i del GOB.

Seguint amb els problemes que genera el règim actual d'accés a l'espai natural, especialment a les platges que alberga i més específicament en el període estiuenc, s'accepta l'al·legació del Consorci de Transports de Mallorca per garantir l'accés d'autobusos a les zones d'accés al futur parc natural, la qual cosa persegueix propiciar l'ús del transport públic, i allunyar el transport privat de les proximitats de les platges.

Igualment es recull gran part de les al-legacions de l'advocacia de la comunitat, per exemple que la declaració d'aparcaments fora d'ordenació ha d'afectar els pàrquings privats d'ús públic, atès que actualment existeixen llocs d'aparcament informal, amb llicència i sense o amb autoritzacions caducades o irregulars, que plantegen problemes seriosos de responsabilitat i d'incompatibilitat amb la conservació dels valors de l'espai natural (que a més és Natura 2000).

Finalment la documentació exposada al públic es complementa amb un estudi d'anàlisi d'alternatives dels aparcaments escollits, basats en un estudi multicriteri. Quant a aquesta 
ubicació d'estacionament de vehicles, es reubica l'aparcament de ses Covetes, i es dona resposta a gran nombre d'al-legacions expressades en aquest sentit que proposen que aquesta zona d'accés i aparcament se situï finalment en una zona que ara mateix ja està degradada i que resulta difícil de recuperar. Igualment, seguint amb la problemàtica derivada dels accessos i l'aparcament (un problema històric i central en aquest espai natural), se suprimeix l'aparcament de la zona de sa Barralina per situar-lo en el nucli urbà de sa Ràpita, a prop de la zona urbana, i en tots els casos es redueixen les dimensions de les zones inicialment previstes com a zona d'estacionament amb la finalitat d'adaptarles a la capacitat real que haurien de tenir, especialment en relació amb la capacitat de càrrega de l'espai natural sensible.

\subsection{Aprovació d'un decret de sequera a Eivissa}

Les Illes Balears estan patint els efectes d'anys d'escassa pluviometria. A Mallorca les reserves en els embassaments es troben en mínims històrics, a Menorca la salinització i la nitrificació de pous planteja problemes seriosos, i a Eivissa s'han hagut d'adoptar mesures extraordinàries mitjançant un decret del Consell de Govern de la Comunitat Autònoma.

Aquest decret declara la situació de sequera extraordinària a l'illa d'Eivissa i adopta mesures urgents i excepcionals de gestió dels recursos hídrics per pal·liar i corregir-ne els efectes. Com a consequiència d'anys de baixa pluviometria i d'una problemàtica estructural de falta d'equilibri en el balanç hídric per sobreexplotació dels aquíffers, l'illa d'Eivissa presenta una situació crítica pel que fa a les reserves d'aigua, consequiència dels dos factors expressats: la manca continuada de precipitacions i la sobreexplotació dels aqüífers.

L'estacionalitat d'aquests factors és incerta, però mentre no es normalitzi el règim de precipitacions i no es busquin fonts de subministrament d'aigua alternatives no naturals, no es pot garantir que es pugui atendre la demanda d'aigua a l'illa. Per això, s'adopta el decret que té com a finalitat controlar al màxim possible la disposició i l'ús d'aigua, i com a objectiu final, recuperar les masses. Això obliga, d'una banda, a adoptar mesures temporals que permetin incrementar el recurs disponible fins que els nivells de reserva millorin, i de l'altra, a adoptar les mesures administratives necessàries que permetin 
corregir aquesta situació mitjançant la limitació i la restricció dels aprofitaments de manera equitativa i solidària entre els sectors afectats.

Per incrementar la disponibilitat d'aigua, el decret preveu que, mentre duri la situació de sequera, no es puguin dur a terme noves captacions en determinades conques que estiguin sobreexplotades d'acord amb el balanç hidrològic. S'exceptuen els aprofitaments per abastir la població, com la geotèrmia, per a la reordenació de cabals sense augment de volum, manteniment i sanejament de pous i dipòsits contra incendis. Per això, en el seu conjunt, les mesures que preveu el decret consisteixen a reduir un $15 \%$ el volum d'extraccions, excepte en l'agricultura, que descendeix un $10 \%$, i en el proveïment en poblacions, les captacions lligades a la lluita contra incendis i en la geotèrmia, que no patiran restriccions.

D’altra banda, aquesta norma també recull la suspensió de la tramitació i de l'atorgament de noves autoritzacions i concessions d'ús i l'obligatorietat dels subministradors (inclosos els de venda d'aigua en camions) d'utilitzar aigua dessalada d'octubre a abril. Els ajuntaments estan obligats a fer estudis de detecció de fuites i presentar-los a l'Administració hidràulica en un termini màxim de 45 dies des de l'entrada en vigor del decret, i dur a terme un pla d'actuació que ha de validar la Direcció General de Recursos Hídrics en cas que les fuites superin el 25\%. Les obres necessàries per als canvis d'ús es consideren d'utilitat pública i de necessitat urgent.

El període d'aplicació i vigència d'aquest decret s'ha d'estendre fins que s'hagi superat el període de sequera. És a dir, quan l'índex publicat al Portal de l'Aigua presenti valors de situació estable durant tres mesos consecutius. No obstant això, algunes de les mesures haurien de mantenir-se com a estructurals durant un dilatat període de temps a la vista del dèficit hídric de l'illa. Igualment no es descarten noves mesures a la mateixa illa d'Eivissa i en la resta de l'arxipèlag.

\section{Polítiques de protecció del medi marí}

\subsection{Aprovada la creació de la Reserva Marina del Freu de sa Dragonera}

Una bona notícia, esperada pel sector pesquer i el de la conservació ambiental, l'ha generat l'aprovació definitiva de l'acord pel qual es crea la Reserva Marina del Freu de sa Dragonera i es regulen les activitats en aquesta àrea. Així, aquesta serà la vuitena reserva marina de l'arxipèlag, amb 912 hectàrees que se sumen a les 58.900 hectàrees ja 
declarades a les illes. D'altra banda, la creació d'aquesta nova reserva respon a les peticions de diversos col-lectius socials i institucions públiques, com l'Ajuntament d'Andratx o el Parlament i altres col-lectius afectats. Amb el Decret es limita l'explotació dels recursos marins vius per incrementar la repoblació d'alevins i protegir els ecosistemes.

El Decret regula les activitats subaquàtiques i d'extracció de flora i fauna marines, en una zona amb uns valors ecològics i pesquers considerables, on es pot trobar una gran diversitat d'hàbitats i comunitats, tal com va posar de manifest l'estudi elaborat el 2004 per al Consell Superior de Recerques Científiques (CSIC) a proposta de la Conselleria de Medi Ambient, Agricultura i Pesca.

En els paisatges submarins de sa Dragonera destaquen les praderies de Posidonia oceanica, molt esteses cap al sud, que actuen com a zones d'elevada producció biològica i d'alevinatge d'espècies d'interès pesquer. Això fa que l'àrea mereixi un alt grau de protecció. Així mateix, la zona inclou part del lloc d'importància comunitària (LIC) de sa Dragonera i forma part de l'entorn marí del parc natural. En aquesta zona tenen lloc activitats que tenen una relació directa amb els recursos pesquers: l'exploten de manera tradicional les embarcacions professionals d'arts menors d'Andratx i les embarcacions recreatives de Sant Elm i el port d'Andratx, i també s'hi du a terme busseig recreatiu. Atès que diversos informes del Servei de Recursos Marins han posat de manifest que les poblacions de peixos vulnerables a la pesca es troben molt per sota del nivell que potencialment podrien presentar, cal regular les actuacions per assegurar un manteniment compatible amb la conservació de la riquesa biològica i dels recursos marins vius.

Entre altres mesures, el Decret prohibeix a la zona els sistemes de pesca més agressius, com ara la pesca submarina, la d'arrossegament o la de cèrcol, i tan sols són autoritzables les modalitats tradicionals de pesca professional d'arts menors i de pesca recreativa de superfície. En relació amb les modalitats de pesca permeses i de les activitats subaquàtiques, la Conselleria de Medi Ambient, Agricultura i Pesca estableix i delimita les zones i els usos permesos(vedes, aparells), d'acord amb els resultats de seguiment i els acords de la Comissió de Seguiment d'aquesta reserva, creada per l'article 8 del mateix decret.

Igualment, aquesta reserva marina es crea d'acord amb la consideració de punt per a l'esperança del mar Balear, declarat pel projecte Mission Blue. L'objectiu de la iniciativa és generar el suport de la societat per protegir aquests llocs mitjançant la creació d'una 
xarxa mundial d'àrees marines protegides que salvaguardin el $20 \%$ dels oceans per a l'any 2020. El mar Balear és l’únic punt amb aquesta consideració en el Mediterrani.

D’altra banda, el Decret conté, a més, una disposició addicional per ampliar la protecció màxima de la Reserva Marina dels Freus d'Eivissa i Formentera fins a la superfície inicial. El 22 de maig de 2015 es van modificar els límits de la zona de protecció màxima de s'Espardell, i es va reduir de manera rellevant l'àrea de la reserva integral, sense que hi hagués cap justificació tècnica o científica. Per això convé ampliar de nou l'àrea de protecció màxima fins a les dimensions originals, per no deixar desprotegides les comunitats de peixos que s'han desenvolupat arran de la protecció que es va decretar el 1999. Així, doncs, es recupera la protecció màxima de cent hectàrees que formen part de les 15.000 que ocupa la Reserva Marina dels Freus d'Eivissa i Formentera, que havien perdut l'estatus de reserva integral.

Com a dada final, cal apuntar que actualment les Illes Balears disposen de set reserves marines, que ocupen una superfície total de 58.900 hectàrees i que són un element bàsic per a la gestió pesquera, ja que es limita l'explotació dels recursos marins vius per incrementar la repoblació d'alevins i fomentar la proliferació de les espècies marines objecte d'explotació o protegir els ecosistemes amb característiques diferenciades.

\subsection{L'ampliació del Parc Nacional Maritimoterrestre de l'Arxipèlag de Cabrera en estudi}

Responent a una reclamació que començava a ser històrica, s'ha encetat un camí amb pas ferm en l'ampliació del Parc Nacional Maritimoterrestre de l'Arxipèlag del Cabrera, amb la creació d'una comissió específica el passat 5 de juliol. Aquesta comissió ha enfocat el seu treball a partir del resultat dels treballs previs de l'equip tècnic del Parc que responen a peticions fetes des d'organitzacions de conservació del medi ambient en general i del marí en particular, com l'organització Oceana. Tal com van establir els acords de governabilitat i com es va acordar en el Consell de Govern, s'ha aprovat la proposta d'ampliació del Parc. En els últims mesos s'han dut a terme les tasques de recollida d'informació i s'han iniciat els contactes corresponents amb els sectors per recollir les primeres impressions sobre la proposta.

Amb aquesta nova proposta d'ampliació es pretén protegir els entorns de l'arxipèlag, que ara estan sotmesos a una pressió excessiva, crear un gran santuari de cetacis al sud i 
incorporar hàbitats que no es troben en cap altre parc nacional. Es debaten tres propostes d'ampliació: una de mínims, de 20.000 hectàrees; una de màxims, de 90.000, i una intermèdia, que permeti assegurar la gestió correcta de l’àmbit marí. En qualsevol cas, la delimitació definitiva es durà a terme després de considerar tota la informació recollida sobre els hàbitats, les pressions i les potencials amenaces. Cal tenir en compte que aquesta proposta d'ampliació de Cabrera afecta principalment aigües exteriors i, per tant, de domini estatal.

Les previsions per a l'ampliació proposada impliquen elaborar en el termini d'un any el document d'ampliació perquè l'Administració autonòmica i l'estatal l'aprovin. El procés inclou una exposició pública de dos mesos com a mètode participatiu que orienti la decisió final que cal adoptar en l'aprovació definitiva.

D'altra banda, l'Organisme Autònom de Parcs Nacionals treballa en noves propostes de creació de parcs nacionals, com ara la d'un parc exclusivament marí a l'illa d'El Hierro, al mar de Las Calmas. Igualment es treballa al parc de la Sierra de las Nieves, a Andalusia.

\subsection{El problema jurídic de les prospeccions al Mediterrani}

A. Es trasllada a Brussel·les la inquietud per les prospeccions

Com hem tractat en anteriors cròniques, l'agenda política de les Illes Balears conté com a assumpte permanentment pendent la preocupació pels projectes de prospeccions i sondejos en aigües del Mediterrani properes al mar Balear. Aquestes concessions plantegen, a més d'un problema ambiental evident, un problema jurídic i de conflicte entre l'Estat i la comunitat autònoma, atès que s'autoritzen i s'exerceixen en aigües pertanyents al mar territorial (aigües exteriors).Tanmateix, això no impedeix que el fort rebuig social que provoquen les prospeccions condueixi també al rebuig del Govern autonòmic, que ha traslladat la queixa i inquietud a la Comissió Europea.

El Govern autonòmic ha mantingut reunions a Brussel-les amb el gabinet del comissari d'Acció pel Clima i Energia, Miguel Arias Cañete, que s'ha interessat per l'estat de cadascuna de les iniciatives en què destaquen tres amenaces: la primera, la d'Spectrum Geo Limited (campanya sísmica 2D a les àrees lliures del Mediterrani nord-occidental), promotora a la qual el Ministeri d'Agricultura, Alimentació i Medi Ambient ha atorgat una pròrroga de nou mesos perquè continuï la tramitació; la segona és la d'Schlumberger, que pot sortir a exposició pública d'impacte ambiental en qualsevol moment; la tercera 
afecta el projecte de MedSalt2, de l'Institut Nacional d'Oceanografia i de Geofísica Experimental de Trieste (Itàlia), que vol trobar grans bancs de sal al Mediterrani al canal de Mallorca i al sud-est de les Pitiüses amb la metodologia de trets disparats amb canons d'aire comprimit.

Cal recordar que aquestes tres iniciatives compten amb l'oposició de tot l'arc parlamentari de les Illes Balears i dels agents socials que s'han anat manifestant en diferents ocasions. Les prospeccions són incompatibles amb la proposta de corredor migratori de cetacis que transcorre entre les Illes Balears i les costes de Catalunya i la Comunitat Valenciana, que es pretén que sigui declarat zona especialment protegida d'importància pel Mediterrani (ZEPIM), proposta que compta amb el suport de la Direcció General de Medi Ambient de la Comissió Europea i del Ministeri espanyol i a la qual dedicarem unes quantes línies en aquesta mateixa crònica.

El Govern ha transmès al gabinet del comissari la queixa que l'Aliança Mar Blava va enviar a la Comissió Europea contra el Govern espanyol, i que aquesta va acceptar, en la qual es criticava que no es tinguessin en compte els efectes acumulatius dels projectes de prospeccions d'hidrocarburs al Mediterrani.

Aquesta negativa a les prospeccions implica buscar alternatives energètiques netes. Per aquest motiu, el Govern autonòmic assumeix que s'han de potenciar les energies renovables. Per això, ha proposat a Brussel-les que, ara que es discuteixen les directives europees en aquest àmbit, no penalitzi l'autoconsum ni la generació d'energies renovables. Igualment es recorda que han d'establir-se primes diferenciades per als territoris insulars, llocs amb una problemàtica molt específica que també han de complir els objectius per al 2020 (20-20-20), tenint en compte que és més complicat implantar grans infraestructures rendibles d'aquesta mena en illes amb territori limitat que en el continent.

\section{B. S'arxiva el procediment impulsat per Schlumberger}

Amb posterioritat al que hem explicat en l'apartat anterior, es va anunciar que el Ministeri d'Agricultura, Alimentació i Medi Ambient arxivaria el projecte de prospeccions de Schlumberger al golf de Lleó, cosa que l'arxipèlag ha acollit molt favorablement. De fet, tant Aliança Mar Blava com la Comissió de Medi Ambient de les Illes Balears havien demanat la caducitat i l'arxiu de l'expedient. 
Així, s’ha fet públic que el Ministeri d’Agricultura, Alimentació i Medi Ambient (MAGRAMA) ha arxivat el projecte "Campanya sísmica en àrees lliures del golf de Lleó davant de les costes de Catalunya i les Illes Balears", que impulsava Schlumberger, després que hagin transcorregut els tres mesos que el MAGRAMA havia atorgat el passat mes de febrer al promotor per aportar informació addicional amb l'objectiu de poder formular la declaració d'impacte ambiental del projecte. La notícia es va transmetre a través d'Aliança Mar Blava, ja que el MAGRAMA no considera l'executiu autonòmic part interessada en la tramitació d'aquests expedients, decisió que recorrerà la Direcció General de Pesca i Medi Marí del Govern de les Illes Balears.

El projecte "Campanya sísmica en àrees lliures del golf de Lleó davant de les costes de Catalunya i les Illes Balears”, impulsat per Seabird Exploration, va començar el 2011, però l'empresa va desistir, i va agafar el relleu Schlumberger, que va continuar tramitant el mateix expedient i en va iniciar un de nou el 2014 amb el mateix objectiu però obviant els tràmits d'exposició pública i de consultes. Després de reiterades peticions d'Aliança Mar Blava i de la Comissió de Medi Ambient de les Illes Balears (CMAIB), al febrer de l'any passat el MAGRAMA va anunciar que arxivaria l'expedient del 2011 relatiu al projecte de prospeccions al golf de Lleó i que iniciaria de nou la tramitació del de 2014, traient-ho a exposició pública i a consulta. Al febrer d'aquest any el MAGRAMA va requerir al promotor que aportés informació addicional per poder formular la declaració d'impacte ambiental del projecte i li va donar un termini de tres mesos per fer-ho. Per això, passat aquest període, la CMAIB, en el Ple de 7 de juliol, va acordar instar el MAGRAMA a declarar la caducitat i l'arxiu de l'expedient, fet que finalment ha succeït.

No obstant això, encara subsisteixen dos projectes què afecten les Illes Balears, un de prospeccions d'hidrocarburs i un altre de recerca salina amb canons d'aire comprimit. En el primer cas, al juny, el MAGRAMA va atorgar una pròrroga de nou mesos a Spectrum Geo Limited perquè continués la tramitació del seu projecte de prospeccions d'hidrocarburs al mar Balear, quan el procediment ja havia caducat, després d'haver-se exhaurit el termini de divuit mesos, que acabava el 20 d'abril, per fer les tramitacions ambientals corresponents.

En el segon cas, la CMAIB també ha demanat al MAGRAMA que el projecte MedSalt2, de l'Institut Nacional d'Oceanografia i de Geofísica Experimental de Trieste (Itàlia), que vol trobar grans bancs de sal al Mediterrani, al canal de Mallorca i al sud-est de les Pitiüses mitjançant trets de canons d'aire comprimit, passi una avaluació d'impacte 
ambiental ordinària i no simplificada, en cas que no s'arxivi el projecte directament. En el mateix sentit s'ha manifestat també Aliança Mar Blava, que recorda, a més, que la conjunció d'aquesta iniciativa i la d'Spectrum a la mateixa regió biogeogràfica determinen potencials impactes acumulatius i sinèrgics que no es poden obviar.

L'acord d'arxiu definitiu es va publicar al BOE en la referència següent de l'enllaç: <https://www.boe.es/diario_boe/txt.php?id=boe-a-2016-9774>.

\section{Polítiques de protecció de la diversitat biològica}

\subsection{Proposta de creació del corredor de cetacis del Mediterrani}

En un apartat anterior s'ha avançat l'existència d'una proposta de corredor migratori de cetacis que transcorre entre les Illes Balears i les costes de Catalunya i la Comunitat Valenciana. Amb aquesta iniciativa es pretén que aquest corredor es declari zona especialment protegida d'importància per al Mediterrani (ZEPIM). Hem de recordar que les ZEPIM són figures de protecció de caràcter internacional declarades arran de la signatura del Protocol sobre les zones especialment protegides i la diversitat biològica del Mediterrani (1995) en el marc del Conveni de Barcelona. Les ZEPIM són un conjunt d'espais costaners i marins protegits que garanteixen la pervivència dels valors i recursos biològics del Mediterrani; contenen ecosistemes típics de la zona mediterrània o hàbitat d'espècies en perill, tinguin un interès científic, estètic o cultural especial.

Continuant amb el treball per a la declaració, s'han mantingut contactes amb les autoritats andaluses que ja en el moment oportú havien participat en un projecte de declaració d'una ZEPIM a l'estret de Gibraltar i d'un parc transcontinental entre Espanya i el Marroc. Ara, la Junta d'Andalusia ha d'estudiar si se suma a la petició de la declaració del Corredor Migratori de Cetacis del Mediterrani Occidental com a zona especialment protegida d'importància pel mediterrani (ZEPIM) en el marc del Conveni de Barcelona.

La Junta d'Andalusia ha acollit positivament la iniciativa $\mathrm{i}$ ha d'estudiar la possibilitat d'ampliar-la perquè protegeixi part de la costa andalusa. Encara que actualment no hi ha cap projecte d'estudi o explotació d'hidrocarburs que afecti Andalusia, existeix un especial interès que s'aprovi una proposta que blindi la costa andalusa davant de possibles futurs projectes. 
Tot apunta que el Govern de les Illes Balears, en col·laboració amb Aliança Mar Blava i els consells insulars i ajuntaments, continuaran l'estratègia de teixir aliances amb altres administracions per arribar a l'objectiu final de detenir les prospeccions a les Illes Balears i assolir un Mediterrani lliure d'aquestes amenaces. A tot això s'hi suma el projecte de ZEPIM amb el corredor de cetacis que es promou ara.

\subsection{Programa de control de serps}

La conservació de la diversitat biològica amb el manteniment de poblacions d'espècies autòctones en bon estat de viabilitat, es veu compromesa amb els fenòmens de globalització i d'introducció d'espècies invasores d'origen exòtic. Aquestes espècies suposen una greu amenaça per a les poblacions de l'arxipèlag, que en alguns casos es veuen seriosament compromeses. En aquest context s'ha iniciat a Eivissa un programa de control de serps amb la instal-lació de 200 gàbies i el seguiment de com incideix la presència d'aquests depredadors al·lòctons en les poblacions de sargantanes. Per la seva banda, el Consell Insular d'Eivissa instal-larà 150 gàbies més en el marc d'aquest programa compartit.

Amb aquest programa de control de serps a Eivissa, que impulsa el Govern amb la col-laboració del Consell Insular de l'illa, es persegueix capturar les serps però també ajudar a conèixer la superfície envaïda i el grau d'invasió, reunir dades de la biologia de les espècies (cicle biològic, alimentació, impactes potencials), potenciar la col-laboració ciutadana i contribuir a la definició de les futures actuacions del problema de les serps invasores des de l'experiència pràctica.

Des de l'any 2003 es produeix l'entrada accidental d'ofidis peninsulars a les Illes Balears. A Mallorca, on ja hi havia constància de dues espècies, se n'han detectat tres més, i a les Pitiüses, on no n'hi havia cap, s'han detectat la serp de ferradura (Hemorrhois hippocrepis) a Eivissa i la serp blanca o d'escala (Rhinechis scalaris) tant a Eivissa com a Formentera. Aquesta introducció d'ofidis en la comunitat autònoma s'ha relacionat directament amb la introducció d'oliveres des del sud de la península en tràilers, per a jardineria ornamental.

És la primera vegada que el Govern col-loca paranys amb aquest propòsit a Eivissa, encara que el Consell Insular ja havia engegat un programa pilot en els anys 2014 i 2015. L'any passat va capturar 121 serps, 117 de les quals eren de ferradura i 4 d'escala; es va 
registrar una mitjana de 0,6 captures per parany i dia en les 19.419 jornades que es van mantenir.

La iniciativa de la Conselleria va començar el 28 de maig amb la instal lació dels primers paranys, i des del 20 de juny compta amb una veterinària del COFIB destinada només a aquest projecte, que disposarà d'un vehicle i d'un espai de treball a les instal-lacions de l'Institut Balear de la Natura (IBANAT) a sa Coma. El programa pilot a les Pitiüses també recull les actuacions a Formentera, on s'han instal. lat 69 dels 100 paranys previstos, que en 1.787 dies han capturat 191 exemplars, mentre que a Eivissa s'han col·locat 40 paranys, on en 378 dies han caigut 45 serps. El 44\% de les serps capturades a Formentera s'han alimentat de sargantanes.

Associat al programa, s'està elaborant un estudi per conèixer de què s'alimenten els ofidis capturats. Aquest estudi elaborat per la Universitat de les Illes Balears (UIB) demostra que el $44 \%$ de les serps que s'han capturat tenien sargantanes a l'estómac, el 65\% tenien algun rosegador i el 14\% havien ingerit tant sargantanes com rosegadors.

Com a acció complementària, el Govern autonòmic treballa en un acord inicial amb el Ministeri d'Agricultura, Alimentació i Medi Ambient i el Govern de Canàries per tirar endavant una estratègia de gestió de les serps invasores en ecosistemes insulars, a més de negociar una moratòria d'importació d'arbres ornamentals fins que s'aprovi aquesta estratègia.

\subsection{Programa de control de la vespa asiàtica}

Una altra de les campanyes que es duen a terme a les illes, més concretament a Mallorca, és la del control de la vespa asiàtica, que s'està convertint en un greu problema en altres comunitats autònomes que amenaça la supervivència de les abelles i de l'apicultura. La vespa asiàtica és una espècie exòtica invasora que depreda activament pol-linitzadors com l'abella de la mel i que causa greus perjudicis en el sector apícola i en els ecosistemes naturals. La vespa asiàtica, Avispa velutina, és un himenòpter exòtic, catalogat com a invasor, que provoca danys greus en les colònies d'abelles (de les quals és un actiu depredador), destrueix molts altres insectes útils i pot suposar un cert risc per a les persones per la mida de l'agulló, encara que no és especialment agressiva.

L'any passat la Conselleria de Medi Ambient, Agricultura i Pesca va retirar un niu de vespa asiàtica al mes de novembre a la zona del Mirador de ses Barques (Sóller), i es van 
eliminar tots els individus de la colònia. El niu, de forma semiesfèrica, pesava uns $8 \mathrm{~kg} \mathrm{i}$ mesurava $70 \mathrm{~cm}$ d'altura. Més recentment es va localitzar un altre niu en el mateix terme municipal de Sóller. En aquests moments, la Conselleria de Medi Ambient, Agricultura i Pesca, el Laboratori de Zoologia de la UIB, l'Ajuntament de Sóller i el COFIB han iniciat les tasques de detecció de noves colònies, amb l'objectiu d'eliminar-les seguint un protocol establert.

El dia 14 de juliol passat un particular va detectar una vespa viva a la proximitat de la vila de Sóller. Immediatament, es va engegar un operatiu per descobrir-ne l'origen, en el qual van participar el COFIB, tècnics del servei d'espècies, agents de Medi Ambient, especialistes de la Universitat i personal de l'Ajuntament de Sóller. La detecció del niu és una tasca molt dificultosa, ja que les vespes es desplacen uns quants quilòmetres per alimentar-se. S'han fet proves, sense èxit, de dotar alguns animals amb emissors de seguiment de 0,42 g, però finalment ha estat el seguiment visual dels animals que ha permès localitzar el niu, a la zona més alta d'un pi, a uns deu metres d'altura. Descartades altres opcions, es va considerar que la millor opció era la retirada manual per part d'especialistes del COFIB amb equipament específic per a aquesta tasca, amb el suport del Cos d'Agents de Medi ambient. L'operació es va fer durant la nit, per garantir la recollida de la totalitat de l'eixam, i posteriorment es va congelar, per sacrificar tota la colònia i continuar la recerca.

Cal tenir present que les colònies estan integrades per uns 2.000 exemplars, i produeixen unes 150 femelles fèrtils per temporada, que solen generar sis nius nous cada any. La progressió, si les colònies no es destrueixen en els primers estadis, pot ser molt ràpida. Actualment, ha ocupat de forma massiva bona part d'Europa occidental, i a l'Estat espanyol, tota la cornisa cantàbrica peninsular i el nord de Catalunya, on les mesures de control es limiten a les zones habitades.

Ara com ara sembla que s'està controlant la presència de la vespa carnissera asiàtica amb el balanç de set nius d'Avispa velutina capturats des de 1'any 2015, la major part dels quals situats a la vall de Sóller. El primer niu es va localitzar a l'octubre del 2015, i durant el 2016 se n'han capturat sis nius més, set en total. Un tret que caracteritza la ubicació de tots els nius és que s'han trobat a la vall de Sóller en un radi d'un màxim de $10 \mathrm{~km}$ de llarg i gairebé sempre en arbres perennifolis, com ara pins, xiprers o alzines. 
El seguiment principal el fa el Cos d'Agents de Medi Ambient, i per facilitar la col-laboració ciutadana s'utilitza una aplicació mòbil, la VespApp o el web $<$ http://vespapp.uib.es>.

\subsection{Programa de potenciació de la posidònia i de control d'espècies invasores}

Les Illes Balears se situen en una zona climàtica òptima per a la conservació de la posidònia, la qual cosa també la fa responsable de la seva conservació i del control de les espècies invasores que poden comprometre l'evolució de les praderies. Per aquest motiu, les Illes Balears han col·locat les espècies invasores i la conservació de la posidònia en l'agenda europea, introduint el problema en el Consell de Ministres de Medi Ambient de la Unió Europea, mitjançant una postura única de les comunitats autònomes. En l'ordre del dia de l'últim Consell es va incorporar una iniciativa legislativa que té a veure amb la proposta de revisió dels sectors no subjectes al règim de comerç de drets d'emissions (ETS) i dues de no legislatives: els projectes de conclusions del Consell sobre el Conveni de biodiversitat biològica i sobre la gestió sostenible de l'aigua.

En aquests punts, les Illes Balears han aconseguit una postura comuna de totes les comunitats, que també té en compte la idiosincràsia de l'arxipèlag. Així, en el Conveni sobre biodiversitat biològica (CBD) s'ha aconseguit tractar l'afectació dels sorolls al mar i la incidència en aquest àmbit dels microplàstics i de la contaminació, que provoquen la pèrdua de biodiversitat marina i costanera. Precisament en aquest mateix document s'ha introduït el punt de les espècies invasores com a prioritari, per poder controlar les vies d'entrada.

\section{Conservació in situ en espais naturals}

\subsection{La zona de Son Bosc es reincorporarà al Parc Natural de s'Albufera}

En un dels primers números de l'RCDA es va tractar el problema de la retirada de la zona de Son Bosc del Parc Natural de s'Albufera de Mallorca. Igualment, en números més recents es va tractar la problemàtica jurídica d'aquesta retirada i de les sentències que han anat recaient en els successius plets interposats. Gràcies a l'acció ciutadana i institucional d'alguns períodes legislatius, Son Bosc tornarà a formar part del Parc Natural de s'Albufera de Mallorca. Així, aprofitant la tramitació de la Llei 12/2016 (que hem 
comentat a l'inici d'aquesta crònica), s'ha propiciat l'ampliació del Parc en derogar, per mitjà de la LEA, la normativa que tenia com a únic objecte fer un camp de golf a la finca, únic motiu per extreure-la del parc. Així, Son Bosc tornarà a formar part del Parc Natural de s'Albufera de Mallorca després que el Parlament aprovés la Llei d'avaluació d'impacte ambiental, que va incloure una disposició derogatòria de la norma que tenia com a únic objecte fer un camp de golf en aquesta finca. Així es compleixen les recomanacions de la Missió d'Assessorament del Conveni Ramsar de 25 de febrer de 2011, que ho indicava explícitament, i també les diferents sentències que han qüestionat la constitucionalitat d'aquesta normativa.

La Llei 9/2010, de 27 de juliol, de declaració d'interès autonòmic de la construcció del camp de golf de Son Bosc, derogava un acord del Consell de Govern d'inici del procediment d'elaboració del Pla d'Ordenació dels Recursos Naturals (PORN) de s'Albufera, i ho feia respecte d'una finca registral concreta, la qual cosa va representar un exemple de legislació a la carta realment denunciable.

El Comitè Ramsar va indicar en el moment oportú que la zona de Son Bosc era una part integral i inseparable de l'ecosistema de s'Albufera, i recomanava "ampliar els límits del lloc Ramsar per incloure Son Bosc i recollir la possibilitat que l'ampliació s'inclogui dins del Parc Natural de s'Albufera de Mallorca". En la mateixa línia, apuntava que "el nou PORN que s'ha d'aprovar per a s'Albufera ha d'incloure la zona de Son Bosc, específicament exclosa de l'inici de PORN actual per la Llei 9/2010”.

Aquesta incorporació compleix així les recomanacions de Ramsar respecte de la zona humida d'importància internacional de s'Albufera de Mallorca, atenent també les consideracions del Tribunal Superior de Justícia de les Illes Balears. Ja en la legislatura 2007-2011 es va promoure l'ampliació de la zona d'especial protecció per a les aus (ZEPA) de s'Albufera de Mallorca, que es va adoptar per mitjà de l'Acord del Consell de Govern el 25 de febrer de 2011, decisió basada en informes tècnics reiterats sobre la importància de la zona de Son Bosc per l'existència de les aus que figuren en l'annex I de la Directiva d'aus.

Per això, l'aprovació de la Llei d'avaluació d'impacte ambiental representa també el vistiplau a la revisió del PORN del Parc Natural de s'Albufera, que com a mínim s'ampliarà fins a Son Bosc, afegint 10 hectàrees a les 1.646,48 existents. 


\subsection{Introducció del milà reial al Parc Natural de Mondragó}

Una de les aplicacions pràctiques de la implantació d'espais naturals protegits i dels seus instruments d'ordenació es manifesta en els programes de conservació in situ mitjançant programes d'introducció d'espècies que s'havien vist desplaçades. Aquest any s'ha detectat que el milà reial (Milvus milvus) ha criat per primera vegada a Mondragó des que es va declarar parc natural, i és que aquesta primavera ha nascut el primer pollet de milana al Parc Natural de Mondragó des que es va declarar espai natural protegit, el 1992. Es tracta d'una parella que l'any passat ja hi havia nidificat però que no havia aconseguit criar, la qual cosa representa un èxit en els objectius de conservació d'aquest espai protegit.

Amb la col-laboració del Grup Balear d'Ornitologia i Defensa de la Naturalesa (GOB) i del Servei d'Agents de Medi Ambient, i amb el suport material d'Endesa, el pollet ha estat anellat (amb marca de lectura a distància) i equipat amb un emissor de seguiment per satèl·lit, que permetrà fer el monitoratge i obtenir informació sobre l'ús que faci del territori.

La milana va ser declarada espècie en perill d'extinció l'any 2003, per la qual cosa la Conselleria de Medi Ambient, Agricultura i Pesca va redactar i va aprovar l'any 2008 un Pla de Recuperació que perseguia l'objectiu de recuperar les poblacions d'aquesta espècie a les Illes Balears fins a situar-les fora de perill, reduint la mortalitat, tant adulta com immadura, i assegurant superfícies extenses d'hàbitats de qualitat.

La milana havia estat una espècie molt comuna en tota l'illa de Mallorca, però en les últimes dècades la població d'aquesta au havia patit un greu descens provocat per motius diversos, com són la desaparició d'hàbitats adequats, l'electrocució en línies elèctriques i sobretot l'enverinament. Actualment, a les Illes Balears hi ha unes cent parelles reproductores. El gruix de la població de milana es concentra principalment a la serra de Tramuntana. El niu de Mondragó és l'únic conegut a la zona del sud-est de Mallorca, fet per la qual és d'especial interès.

L'objectiu principal d'un parc natural és la conservació de la biodiversitat. Per això, la cria del milà reial a Mondragó representa un dels millors beneficis que es poden esperar d'un espai natural protegit: contribuir a la recuperació d'espècies en perill d'extinció. 


\subsection{Cria de l'ibis negre al Parc Natural de s'Albufera de Mallorca}

En la mateixa línia que la notícia anterior, recollim una altra novetat, i és que l'ibis negre ha criat per primera vegada a s'Albufera de Mallorca i, de fet, i que se'n tingui constància, és la primera vegada que es documenta un cas a les Illes Balears. Des de fa anys al Parc Natural de s'Albufera de Mallorca diverses espècies de garses crien conjuntament en un petit tram de bosc de ribera i formen una impressionant colònia reproductora mixta, amb desenes de parelles d'agrons blancs (martinet blanc o garseta blanca) (Egretta garzetta), esplugabous (Bubulcus ibis), orvals (martinet de nit) (Nycticorax nycticorax) i torets (martinet ros o orovals) (Ardeola ralloides). Totes aquestes espècies van colonitzar les Illes Balears com a reproductors gràcies precisament a l'establiment d'aquesta colònia. Aquest any, una nova espècie, la cinquena que es documenta, s'ha sumat a les quatre que ja criaven. No ha estat una garsa sinó una espècie d'ibis, l'ibis negre o capó reial (Plegadis falcinellus). L'ibis negre és l'única espècie de la seva família nativa del continent europeu, on és escassa. Està catalogada "d'interès especial”, i en el Llibre vermell de les aus d'Espanya es considera una espècie vulnerable. A s'Albufera s'han trobat aquests dies dos nius amb pollets, i se sospita de la presència d'un o dos nius més.

\section{Polítiques sobre els recursos hídrics}

En relació amb la crònica relativa a l'aprovació del Decret de sequera a Eivissa, podem completar la notícia amb el relat d'una sèrie de mesures complementàries destinades a fomentar l'estalvi d'aigua a l'arxipèlag, en aquest cas mitjançant una campanya de conscienciació d'estalvi d'aigua en els establiments hotelers.

Així, en el marc de la campanya de sensibilització d'estalvi en el consum d'aigua, s'han editat 51.500 cartells per col·locar en els poms de les portes, 25.750 en anglès i l'altra meitat en alemany, que completen tot un seguit de peces creades amb el lema: "L'aigua és un bé escàs. Pensa-hi!”. El cartell, que es penjarà a les portes dels sanitaris i de les cuines, recull consells de bones pràctiques per estalviar aigua en apartaments, hotels i altres instal·lacions de restauració.

Amb aquest material es convida als turistes a participar en la campanya de difusió i conscienciació per a un ús racional de l'aigua, que s'ha creat amb una imatge pròpia en diferents formats i estils, i que serveix per identificar el moment actual de prealerta per sequera i sensibilitzar la població i els visitants, especialment durant la temporada 
turística, de màxima pressió per a aquest recurs. Aquesta acció se suma a altres iniciatives que s'han dut a terme en el marc de la campanya de conscienciació d'estalvi d'aigua, que va començar amb un espot que s'ha convertit en viral a les xarxes socials.

Es pot accedir a la campanya des d'aquest enllaç publicat al web del Govern: $<$ http://www.caib.es/govern/sac/fitxa.do?codi=2608586\&coduo=138143\&lang=ca $>$.

\section{Política de residus}

La gestió de residus a les Balears corre diferent sort en les diferents illes. La competència dels residus no perillosos pertany als consells insulars, i la gestió i el tractament dels perillosos depèn del Govern autonòmic. Amb tot, a les quatre illes la gestió dels residus planteja seriosos problemes derivats del fet insular i d'una gestió històrica deficient. Una anomalia que comentarem a continuació es posa de manifest en relació amb el tractament dels residus d'envasos, que disposa d'una comissió de seguiment amb el gestor ECOEMBES, que no es reunia des del 2011. Aquesta comissió deriva del conveni marc subscrit en el moment oportú i l'operativitat n'havia quedat seriosament qüestionada.

Aquesta comissió està integrada pel Govern, els consells insulars, EMAYA (empresa de residus de Palma de Mallorca) i la FELIB (Federació d'Entitats Locals de les Illes Balears), a més d'ECOEMBES. Amb aquest òrgan es pretenen dos objectius: complir el conveni signat, que obliga a crear una comissió per fer el seguiment i amb el compromís de facilitar totes les dades de les quals es disposi — en aquest cas, de la recollida d'envasos lleugers i de paper i cartró- i aprofitar l'espai per compartir i resoldre problemes i experiències.

La convocatòria de la Comissió de Seguiment del conveni marc amb ECOEMBES, va tenir lloc després de quatre anys sense haver-se dut a terme. En aquest context, el Govern ha restablert els contactes amb prop de vint sistemes col-lectius de responsabilitat ampliada del productor que treballen a les Illes Balears, per activar campanyes de comunicació, sensibilització i bones pràctiques, i recuperar una relació directa que s'havia perdut, oferint la col-laboració de l'executiu autonòmic. En aquest àmbit s'estan revisant accions i convenis, com el d'Ecovidrio; s'han mantingut reunions amb Ambilamp per reforçar la implantació de punts de recollida de lluminària fluorescent, i es negocia una campanya en tallers mecànics amb Sigaus (entitat que gestiona l'oli industrial usat, com 
el dels cotxes). A part, estan en marxa les campanyes de SIGRE, per recollir medicaments caducats, i d'Ecopilas.

En la Comunitat Autònoma de les Illes Balears estan autoritzats prop d'una vintena de sistemes col-lectius de responsabilitat ampliada que gestionen entitats sense ànim de lucre i que es responsabilitzen de la gestió correcta dels residus que es generen al final de la vida útil dels productes que es posen al mercat: envasos lleugers, de vidre i de paper o cartó, les piles i els acumuladors, els pneumàtics fora d'ús, els olis industrials usats, els envasos de medicaments i els medicaments caducats, els envasos de productes fitosanitaris i els residus d'aparells elèctrics i electrònics.

\section{Sobre l'aplicació de l'impost de turisme sostenible}

Un dels projectes legislatius estrella de l'actual Govern ha estat l'aprovació de la Llei 2/2016, de 30 de març, de l'impost sobre estades turístiques i de mesures d'impuls del turisme sostenible. Una de les accions de gestió de l'impost implica decidir-ne la destinació finalista. Per això, el Govern, a través de la Conselleria de Medi Ambient, Agricultura i Pesca prepara projectes per al medi rural que es puguin beneficiar de l'impost de turisme sostenible. Com a primera mesura s'està treballant en l'anomenat contracte agrari, una de les demandes de l'organització agrària Unió de Pagesos, destinat a les explotacions més clàssiques i familiars amb policultius (com a ramat, cereals i hortalisses), que normalment queden al marge de les línies d'ajuda ordinàries.

Probablement, des d'una perspectiva de preservació del paisatge agrícola, aquesta destinació és una bona aportació derivada l'impost, junt amb una millor dotació dels recursos destinats a la protecció i gestió dels espais naturals protegits i els recursos naturals més vulnerables com l'aigua. 